\title{
Rock Physics of Geologic Carbon Sequestration/Storage
}

Type of Report:

Reporting Period Start Date:

Reporting Period End Date:

Principal Authors:

Date Report was issued:

DOE Award Number:

Submitting Organization:

Principal Investigator:
Final Scientific/Technical

December 1, 2009

May 31, 2013

Dr. Jack Dvorkin and Dr. Gary Mavko

August 2013

DE-FE0002190 (SPO\# 47004)

The Leland Stanford Junior University 340 Panama Street

Stanford, CA 94305-4100

Dr. Gary Mavko

Phone: 650-723-9438

Email: mavko@stanford.edu

U.S. Department of Energy

National Energy Technology Laboratory

DOE Project Manager, Karen Kluger 


\section{Disclaimer}

This report was prepared as an account of work sponsored by an agency of the United States Government. Neither the United States Government nor any agency thereof, nor any of their employees, makes any warranty, express or implied, or assumes any legal liability or responsibility for the accuracy, completeness, or usefulness of any information, apparatus, product, or process disclosed, or represents that its use would not infringe privately owned rights. Reference herein to any specific commercial product, process, or service by trade name, trademark, manufacturer, or otherwise does not necessarily constitute or imply its endorsement, recommendation, or favoring by the United States Government or any agency thereof. The views and opinions of authors expressed herein do not necessarily state or reflect those of the United States Government or any agency thereof. 


\begin{abstract}
This report covers the results of developing the rock physics theory of the effects of $\mathrm{CO}_{2}$ injection and storage in a host reservoir on the rock's elastic properties and the resulting seismic signatures (reflections) observed during sequestration and storage. Specific topics addressed are: (a) how the elastic properties and attenuation vary versus $\mathrm{CO}_{2}$ saturation in the reservoir during injection and subsequent distribution of $\mathrm{CO}_{2}$ in the reservoir; (b) what are the combined effects of saturation and pore pressure on the elastic properties; and (c) what are the combined effects of saturation and rock fabric alteration on the elastic properties. The main new results are (a) development and application of the capillary pressure equilibrium theory to forecasting the elastic properties as a function of $\mathrm{CO}_{2}$ saturation; (b) a new method of applying this theory to well data; and (c) combining this theory with other effects of $\mathrm{CO}_{2}$ injection on the rock frame, including the effects of pore pressure and rock fabric alteration. An important result is translating these elastic changes into synthetic seismic responses, specifically, the amplitude-versus-offset (AVO) response depending on saturation as well as reservoir and seal type. As planned, three graduate students participated in this work and, as a result, received scientific and technical training required should they choose to work in the area of monitoring and quantifying $\mathrm{CO}_{2}$ sequestration.
\end{abstract}




\section{Table of Contents}

Executive Summary

Results and discussions $\quad 6$

Observations of the elastic signatures of $\mathrm{CO}_{2}$ sequestration 6

Capillary pressure equilibrium theory (CPET) 8

$\begin{array}{ll}\text { Synthetic seismic signatures } & 21\end{array}$

Practical fluid substitution on well data $\quad 30$

Additional comments on fluid substitution effects 38

Changes in elastic properties of dry frame and its seismic effects 39

Conclusion $\quad 53$

Graphical materials list $\quad 54$

References and bibliography $\quad 59$

$\begin{array}{ll}\text { Acronims and abbreviations } & 61\end{array}$ 


\section{Executive Summary}

This work has been directly aimed at two focal areas of R\&D: (a) geologic carbon storage and (b) monitoring, verification, and accounting (MVA) of $\mathrm{CO}_{2}$. It also implicitly addresses two other focal areas: (c) capture of $\mathrm{CO}_{2}$ and (d) simulation and risk assessment. This effort has been focused on the development of theoretical rock physics models that can predict the changes in elastic response as a function of $\mathrm{CO}_{2}$ quantity insitu and alterations in the rock texture due to mechanical and chemical processes. The reported results will directly help in (a) quantifying remote seismic data in terms of MVA of $\mathrm{CO}_{2}$ and (b) selecting formations most suitable for geologic $\mathrm{CO}_{2}$ sequestration.

This work has been conducted by three doctoral students under the supervision of a teaching professor (PI) and a senior research scientist. By conducting fundamental research, these graduate students will acquire unique technical skills in quantifying changes in rock properties during injection and storage of $\mathrm{CO}_{2}$ and, as a result, will advance science in the said topics and become experts in predicting and monitoring the quantities of $\mathrm{CO}_{2}$ stored in the host formation as well as its movement and redistribution in the subsurface.

This project has partly quantified the still qualitative concept of rock-frame changes during $\mathrm{CO}_{2}$ injection and storage, help discriminate the effects of mineral framework alteration from saturation, and, by so doing, create a new physics-based methodology of MVA.

Specific topics covered are: (a) how the elastic properties and attenuation vary versus $\mathrm{CO}_{2}$ saturation in the reservoir during injection and subsequent distribution of $\mathrm{CO}_{2}$ in the reservoir; (b) what are the combined effects of saturation and pore pressure on the elastic properties; and (c) what are the combined effects of saturation and rock fabric alteration on the elastic properties. The main new results are (a) development and application of the capillary pressure equilibrium theory to forecasting the elastic properties as a function of $\mathrm{CO}_{2}$ saturation; (b) a new method of applying this theory to well data; and (c) combining this theory with other effects of $\mathrm{CO}_{2}$ injection on the rock frame, including the effects of pore pressure and rock fabric alteration.

An important result is translating these elastic changes into synthetic seismic responses, specifically, the amplitude-versus-offset (AVO) response depending on saturation as well as reservoir and seal type. As planned, three graduate students participated in this work and, as a result, received scientific and technical training required should they choose to work in the area of monitoring and quantifying $\mathrm{CO}_{2}$ sequestration. 


\section{RESULTS AND DISCUSSIONS}

\section{Observations of the Elastic Signatures of $\mathrm{CO}_{2}$ Sequestration}

The goal of this task was to create a database of laboratory and filed observations of the effects of $\mathrm{CO}_{2}$ sequestration on the elastic and textural properties of the host reservoir.

Siggins (2005) presented velocity measurements on several sandstone samples, airdry as well as saturated with gas and liquid $\mathrm{CO}_{2}$, at varying differential pressure. The results indicate very small elastic-wave-velocity difference between the three saturation scenarios. However, the attenuation measured on the samples with liquid $\mathrm{CO}_{2}$ is slightly larger (about 20\%) than that measured on air-dry samples.

Vanorio et al. (2008) show that $\mathrm{CO}_{2}$ injection into carbonate samples acts to soften

these samples. These results were confirmed in later experiments conducted at the Stanford Rock Physics Laboratory.

Daley et al. (2007) reported the results of continuous active-source monitoring of $\mathrm{CO}_{2}$ injection into brine aquifer. The results indicate changes in the wave travel time corresponding to $\mathrm{CO}_{2}$ appearance at the monitoring well.

Raef et al. (2005) conducted rock-physics-based synthetic seismic study for monitoring enhanced oil recovery in thin carbonate layer due to $\mathrm{CO}_{2}$ flooding. They computed instantaneous frequency section of the thinning-layer synthetics and amplitude variations in time-window of the layer.

Li et al. (2006) conducted fluid-substitution modeling for Perth Basin to predict 4D seismic response changes.

Lumley (2010) presented seismic processing techniques for better imaging of $\mathrm{CO}_{2}$ sequestration. This work showed the improvement in the imaging of the weak injection anomalies as compared to the conventional processing results.

Urosevich et al. (2010) presented seismic evidence of changes in the elastic properties of a sandstone reservoir due to $\mathrm{CO}_{2}$ injection for time-lapse seismic monitoring of $\mathrm{CO}_{2}$ injection into a depleted gas reservoir in Naylor Field, Australia.

Chadwick et al. (2010) presented seismic evidence of significant changes in the 
elastic properties of a sandstone reservoir in the North Sea (Sleipner) due to $\mathrm{CO}_{2}$ injection.

Purcell et al. (2010) presented a combination of laboratory work and seismic interpretation for SACROC oil field in the Permian Basin in western Texas, the oldest CO2 enhanced oil recovery site in the United States. High reflectivity was interpreted as an indication of the presence of supercritical $\mathrm{CO}_{2}$ in the subsurface.

These data indicate that, as with any time-lapse seismic monitoring, the observed changes in the seismic response during $\mathrm{CO}_{2}$ sequestration are often far from being quantitative, meaning that even if a seismic event points to the presence of $\mathrm{CO}_{2}$ in the subsurface, quantifying its quantity remains a difficult task.

With this is mind and also being convinced that any interpretation has to be physicsbased, we have proceeded with a rigorous rock physics study of the effects of saturation as well as alterations in the rock fabric on the seismic reflections of $\mathrm{CO}_{2}$ sequestration. 


\section{Capillary Pressure Equilibrium Theory (CPET)}

Capillary Drainage. As gas is injected into a brine-filled reservoir, it replaces the brine. A dominant mechanism is called drainage. Conceptually, one drainage mechanism occurs as the capillary pressure in the system increases due to gas injection. This concept is based on the assumption that at each (increasing) injection pressure station, the brine, which is the wetting fluid, is gradually pushed out of the pores, initially from large pores and, eventually, from smaller capillaries. This process is quasi-static, meaning it is slow. This means that at high injection pressure, this drainage does not happen in the immediate vicinity of the injection well, but as the injected gas propagates into the reservoir, the capillary pressure drainage becomes dominant.

Brooks and Corey (1964) introduced an empirical equation for the reduction of water saturation $S_{w}$ with the increasing capillary pressure $P_{c}$ :

$$
S_{w}=S_{w i}+\left(1-S_{w i}\right)\left(P_{t} / P_{c}\right)^{\lambda}
$$

where $S_{w i}$ is the irreducible water saturation; $P_{t}$ is the so-called threshold pressure; and $\lambda$ is an empirical coefficient. If the capillary pressure $P_{c}$ equals the threshold pressure $P_{t}$, the water saturation $S_{w}$ is 1.00 (or 100\%). This means that drainage cannot start until the capillary pressure on the inlet exceeds the threshold pressure. On the contrary, as $P_{c}$ becomes much larger than $P_{t}$, the second term in Equation 2.1 approaches zero and, as a result, the water saturation approaches the irreducible water saturation below which the rock cannot be drained.

Thomas (1968) experimentally related $P_{t}$ to the absolute permeability $k$ as

$$
P_{t}=52 k^{-0.43} \text {, }
$$

where $k$ is in $\mathrm{mD}$ and is in $\mathrm{kPa}$. Naturally, $P_{c}$ in Equation 2.1 also has to be in $\mathrm{kPa}$.

Dataset. Let us compute $P_{t}$ for a laboratory dataset obtained on a number of unconsolidated sand samples from the Troll field in the North Sea (Figure 2.1). Because, in spite of representing a gas field, the Troll samples are typical for unconsolidated highporosity offshore saline reservoirs, essentially across the world, that may be desirable targets for $\mathrm{CO}_{2}$ sequestration. The theoretical models developed in the course of this 
project will be tested and illustrated on this dataset. The elastic-wave velocity in the Troll room-dry samples was measured at varying confining pressure. In this case we will use two sets of these measurements: at 15 and $30 \mathrm{MPa}$ confining stress and essentially zero (atmospheric) pore pressure. These data are plotted in Figure 2.1.
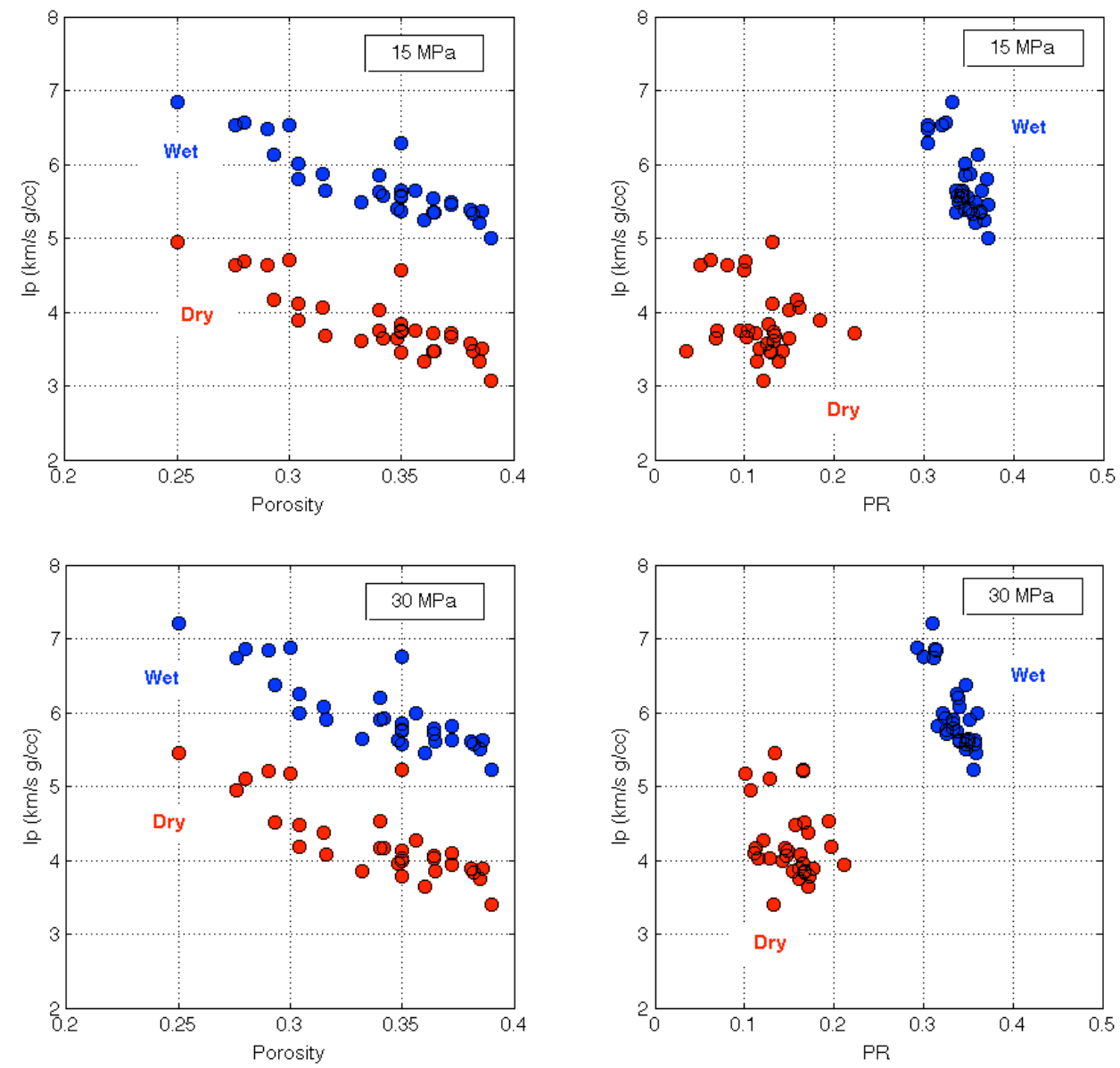

Figure 2.1. The P-wave impedance versus porosity (left column) at 15 (top) and 30 (bottom) MPa confining stress for dry (red) and fully water saturated (wet) conditions (blue). The P-wave impedance versus Poisson's ratio (right column) with the same notations as the plots on the left.

The absolute permeability measured on the Troll samples is plotted versus porosity in Figure 2.2 (left). In the same figure (right), we plot the threshold capillary pressure as given by Equation 2.2. This equation implies that the larger the permeability the smaller the threshold pressure. This relation appears to make physical sense since often large permeability is associated with wide capillaries in the rock where it is easy to replace water with gas and, conversely, small permeability is associated with narrow capillaries 
where the surface tension strongly resists drainage.
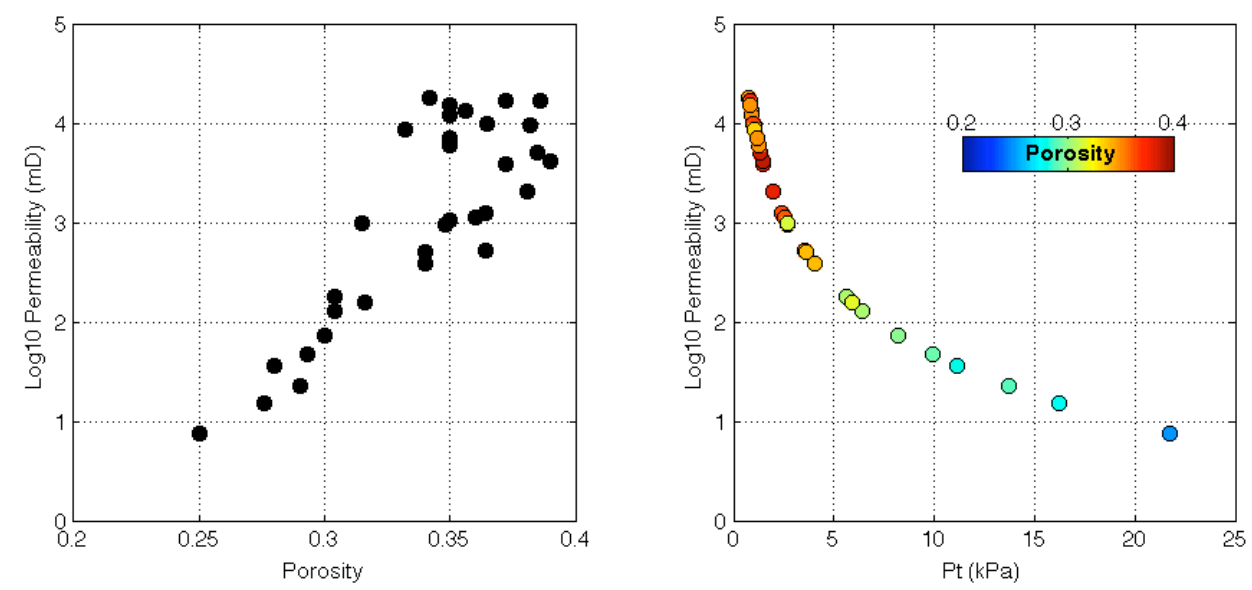

Figure 2.2. Permeability versus porosity (left) and permeability versus the threshold pressure (right), color-coded by the porosity of the samples.

Equation 2.1 allows us to compute the changes in water saturation as the capillary pressure increases and gradually drains the rock by replacing the brine with $\mathrm{CO}_{2}$ gas. The water saturation $S_{w}$ is $100 \%$ for $P_{c}=P_{t}$ and gradually decreases with increasing $P_{c}$. To illustrate this effect, let us choose $P_{t}=5 \mathrm{kPa}$ and compute $S_{w}$ using Equation 2.1. The irreducible water saturation (see equations below in the text) is chosen 0.30 for this example. Water saturation computed from Equation 2.1 is plotted versus $P_{c}$ in Figure 2.3 and for $\lambda=1.00,1.25$, and 1.50. As we can see from Figure 2.3, the selection of $\lambda$ does not significantly affect the resulting water saturation versus capillary pressure curves.

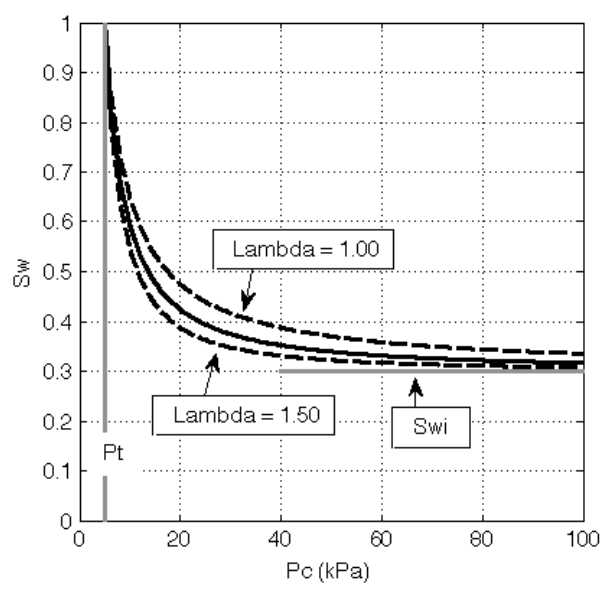

Figure 2.3. Water saturation versus capillary pressure according to Equation 2.1, for irreducible water saturation 0.30 and $\lambda=1.00,1.25$ (solid curve), and 1.50. 
The constant $\lambda$ in Equation 2.1 depends on lithology. Walls and Amaefule (1985) indicate (from mercury injection experiments on sandstone samples) that $\lambda$ can vary between 1.00 and 1.50. In the following computations, we will use $\lambda=1.25$. An example shown below indicates that the elastic properties of rock at partial saturation computed using the capillary pressure equilibrium theory is fairly insensitive to the value of $\lambda$ within the 1.00 to 1.50 interval.

Irreducible Water Saturation. One possibility for estimating the irreducible water saturation $S_{w i}$ is from Timur's (1968) equation that is an empirical equation linking the absolute permeability to porosity and $S_{w i}$ as

$$
k=8581 \phi^{4.4} / S_{w i}^{2},
$$

where $k$ is in $\mathrm{mD}$ and both porosity and saturation are in fraction of one. As a result,

$$
S_{w i}=92.63 \frac{\phi^{2.2}}{\sqrt{k}},
$$

where the units used in Equation 2.3 have to be used.

Equation 2.4 can be further expanded if we recall the Kozeny-Carman permeability equation (Mavko et al., 2009) that relates the absolute permeability $k$ to the grain size $d$ :

$$
k=d^{2} \frac{10^{9}}{72} \frac{\left(\phi-\phi_{p}\right)^{3}}{\left[1-\left(\phi-\phi_{p}\right)\right]^{2} \tau^{2}},
$$

where $\phi_{p}$ is the percolation (or threshold) porosity at which the pore space becomes disconnected and, hence, the permeability becomes zero; $\tau$ is the unitless tortuosity; $d$ is in $\mathrm{mm}$; and the resulting $k$ is in $\mathrm{mD}$. A reasonable range for $\phi_{p}$ is between zero and 0.03. The tortuosity for medium-to-high porosity sandstone is between 2.0 and 3.0.

By combining Equations 2.4 and 2.5 we can relate the irreducible water saturation to porosity, grain size, and tortuosity as

$$
S_{w i}=\frac{0.025}{d} \frac{\phi^{2.2}\left[1-\left(\phi-\phi_{p}\right)\right] \tau}{\left(\phi-\phi_{p}\right)^{1.5}},
$$

where the units are the same as in Equations 2.4 and 2.5. For $\phi_{p}=0$, Equation 2.6 reads 


$$
S_{w i}=0.025 \frac{\phi^{0.7}(1-\phi) \tau}{d}
$$

For a porous system with mixed particle sizes, the effective particle size that can be used in the Kozeny-Carman equation is the harmonic average of the individual particle sizes (Mavko et al., 2009). Specifically, if the particle size in the sand is $d_{S S}$ and that in the shale (clay) is $d_{S H}$, the effective particle size $d$ is

$$
d=\left(\frac{1-C}{d_{S S}}+\frac{C}{d_{S H}}\right)^{-1} .
$$

The range of the grain sizes in sand is between 0.050 and $2.000 \mathrm{~mm}$, it is between 0.002 and 0.050 in silt, and less than $0.002 \mathrm{~mm}$ in clay. Figure 2.4 (left) shows how the effective grain size varies with the shale (clay) content for $d_{S S}=0.010 \mathrm{~mm}$ and $d_{S H}=$ $0.001 \mathrm{~mm}$.
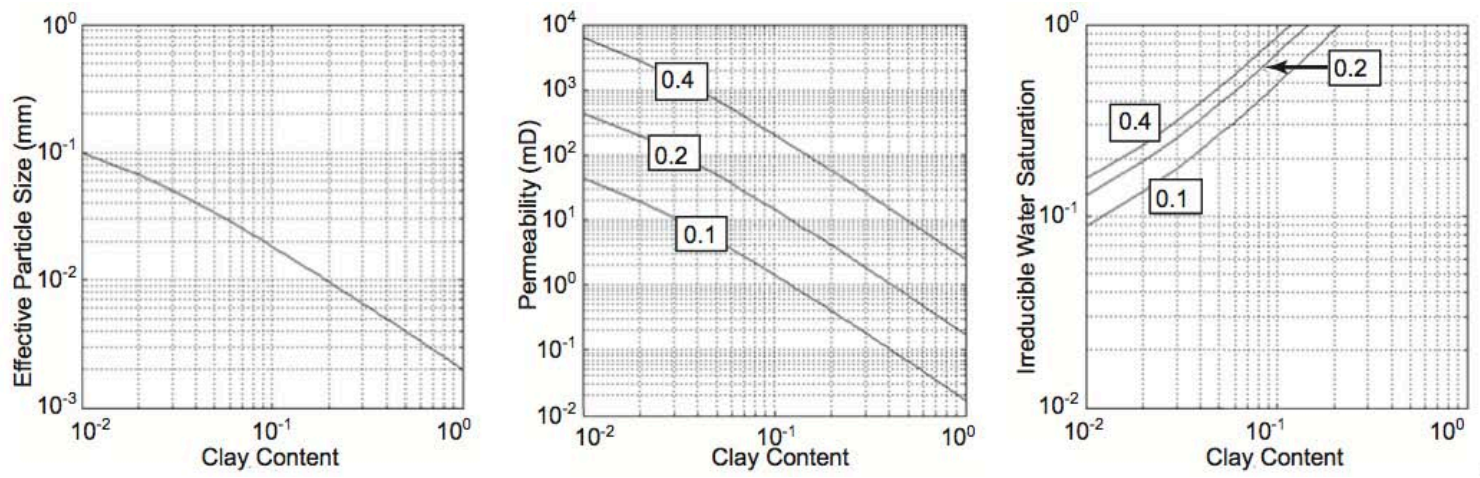

Figure 2.4. Left: The effective grain size versus the clay content according to Equation 2.8 and for the sand grain size $0.200 \mathrm{~mm}$ and shale grain size $0.002 \mathrm{~mm}$. Middle: Permeability versus the clay content according to Equation 2.5 with the percolation porosity zero, tortuosity 2, and the sand and shale grain sizes used for the plot on the left. Permeability is computed for porosity $0.4,0.2$, and 0.1 as marked in the plot. Right: The irreducible water saturation versus the clay content for the same inputs and three porosity values.

The drastic permeability reduction with the increasing clay content is illustrated by the experimental data from Yin (1992) obtained on mixtures of Ottawa sand and kaolinite clay (Figure 2.5). These data were obtained at room conditions at which the porosity of pure kaolinite is very high, in excess of 0.6. As the clay content steadily increases from zero to $100 \%$, we first observe porosity reduction from that of the pure sand (about 0.40 ) 
to its minimum value (about 0.35 ) followed by monotonic porosity increase to that of the pure clay. This is why in the permeability-porosity plot in this figure we observe somewhat counterintuitive reduction of permeability with increasing porosity.
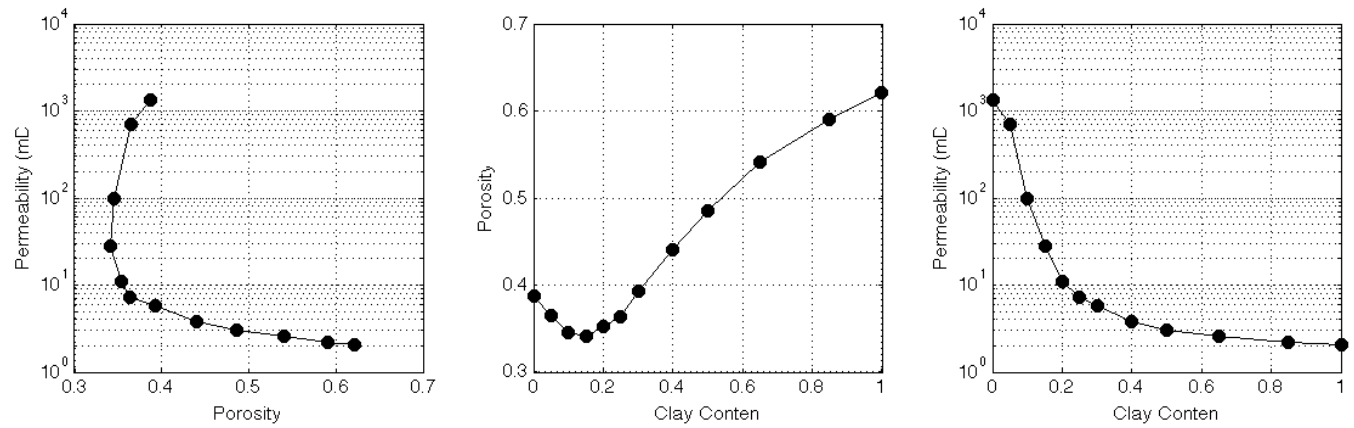

Figure 2.5. Ottawa sand and kaolinite mixtures (Yin, 1992). Left: Permeability versus porosity. Middle: Porosity versus clay content. Right: Permeability versus clay content.

Elastic Properties at Partial Water Saturation. To simulate water drainage in rock, we need to assume that a sample of rock is heterogeneous. To simplify the task, we also assume that it is made of a number of equal-volume subsamples with rock properties varying among these subsamples. It is convenient to visualize this composite sample as a cube consisting of smaller cubical subsamples. The properties of these subsamples (porosity, permeability, and the elastic moduli) can be randomly drawn from a dataset (in this case we will use the Troll data) or generated using rock physics models that relate the elastic properties to porosity and mineralogy and permeability to porosity and mineralogy. For an exhaustive overview of the moduli-porosity-mineralogy relations, see Mavko et al. (2009). An example of relating permeability to porosity and clay content is given earlier in this text.

Figure 2.6 is an example of such a composite cube. Let us assume that in the beginning of the drainage process, all subsamples are fully water saturated. Next, we increase the capillary pressure simultaneously in each subsample and start replacing water with gas. This assumption that each subsample drains simultaneously and independently of its surroundings is one of the major assumptions of the CPET theory. As the capillary pressure increases, it will become larger than the threshold pressure in some of the subsamples but will remain below the threshold pressure in the others. The 
former will become partially saturated while the latter remain fully wet.

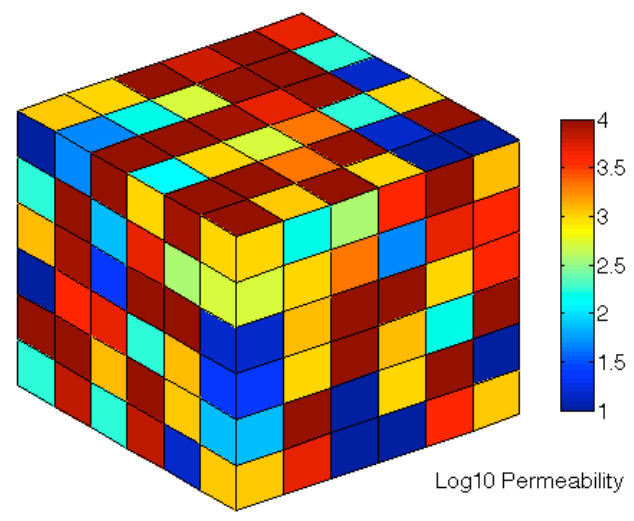

Figure 2.6. Permeability variation within a composite cube made of 216 (6 x 6 × 6) subsamples randomly drawn from the Troll dataset.

The elastic properties of the composite cube will be computed as the arithmetic average of the upper and lower elastic bounds based on the individual elastic moduli of the subsamples. The specific bounds used here are the upper and lower HashinShtrikman bounds (e.g., Mavko et al., 2009). These bounds are appropriate for an isotropic composite, which is another assumption of the theory (that the composite sample is elastically isotropic). Unlike the first assumption, this assumption is not very restrictive: in principle, we can construct an anisotropic composite made of isotropic subsamples and find the bounds for its elastic properties. Here, we concentrate only on elastically isotropic rock.

Because the elastic properties of the subsamples drawn from the same dataset are not drastically different from each other, the lower and upper Hashin-Shtrikman bounds are very close to each other and, hence, their arithmetic average is an accurate approximation for the effective elastic properties of the composite.

The elastic properties of each subsample of the composite thus generated are computed from the subsample's dry-rock elastic moduli via Gassmann's fluid substitution. Within each subsample, we assume that the bulk modulus $K_{f}$ of the "effective" pore fluid that includes brine and gas is the harmonic average of the respective bulk moduli of these two fluid phases: 


$$
K_{f}=\left(\frac{S_{w}}{K_{w}}+\frac{1-S_{w}}{K_{g}}\right)^{-1},
$$

where $K_{w}$ and $K_{g}$ are the bulk moduli of the brine and gas, respectively, and $S_{w}$ is the local water saturation in the subsample. The global water saturation in the composite sample is the arithmetic average of the local saturation values.

Everywhere in this report, we will call this method of fluid substitution, where the bulk modulus of the "effective" pore fluid is the harmonic average of the individual bulk moduli, traditional or Gassmann's fluid substitution. Strictly speaking, this method should not be called "Gassmann's" since the method of harmonic averaging of the fluid phase bulk moduli is completely separate from the original Gassmann's equation. Nevertheless, the name has been historically accepted and we will use it in this report.

The CPET workflow is to compute the water saturation in each subsample as the capillary pressure increases; compute the effective elastic properties of each subsample as a function of local water saturation; compute the effective elastic properties of the composite as the average between the lower and upper Hashin-Shtrikman bounds; and, finally, relate these properties to the global saturation.

Examples. The examples shown here are computed using the Troll dataset and the following elastic properties for brine and $\mathrm{CO}_{2}$ gas that correspond to pore pressure 15 $\mathrm{MPa}$ and temperature $60 \mathrm{C}^{\circ}$ : the bulk modulus and density of brine are 3.019 GPa and $1.075 \mathrm{~g} / \mathrm{cc}$, respectively, while these properties of the gas are $0.045 \mathrm{GPa}$ and $0.573 \mathrm{~g} / \mathrm{cc}$, respectively. In the following simulations, we will use $7^{3}=343$ subsamples randomly drawn from the Troll dataset. We will compare the resulting impedance versus saturation and Poisson's ratio versus saturation curves with traditional fluid substitution for the composites thus generated where the global bulk modulus of the fluid in the entire composite is the harmonic average of those of the brine and gas (Equation 2.9) and assuming that water saturation is the same and equal the global water saturation in each subsample. The computations have been conducted for about 200 random realizations of drawing individual subsamples from the Troll dataset.

Figure 2.7 shows the P-wave impedance $I_{p}$ (left) and Poisson's ratio $v$ (right) versus water saturation as computed according to the capillary pressure equilibrium theory and 
using traditional (Gassmann’s) fluid substitution theory on the entire composite cube. The elastic Troll data used in this example is for $15 \mathrm{MPa}$ confining stress. We observe a fairly large difference between the two fluid substitution methods for both $I_{p}$ and $v$. Because seismic reflections strongly depend on both elastic parameters, we expect a discernable difference between the synthetic seismic amplitude versus saturation as computed by these two methods. Figure 2.8 is the same as Figure 2.7 but for the elastic data at $30 \mathrm{MPa}$ confining pressure.
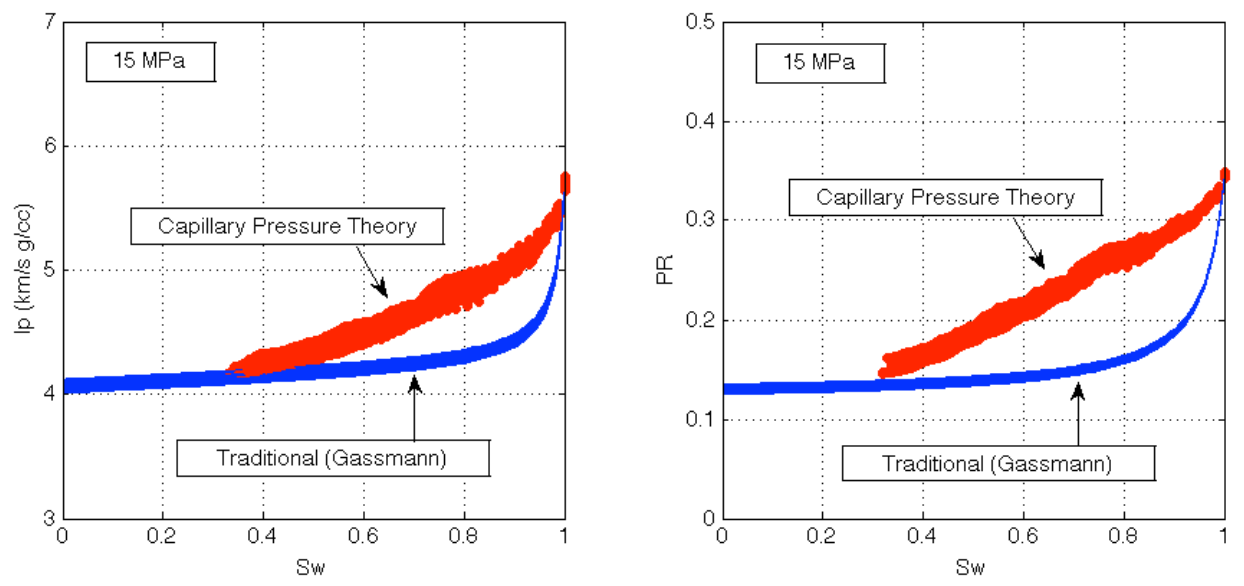

Figure 2.7. Impedance (left) and Poisson's ratio (right) versus global water saturation in a composite 343-element cube built from the Troll dataset samples with the elastic properties measured at $15 \mathrm{MPa}$ confining stress. Red symbols are according to CPET while blue curves are according to traditional Gassmann’s fluid substitution. The results are for about 200 random realizations.
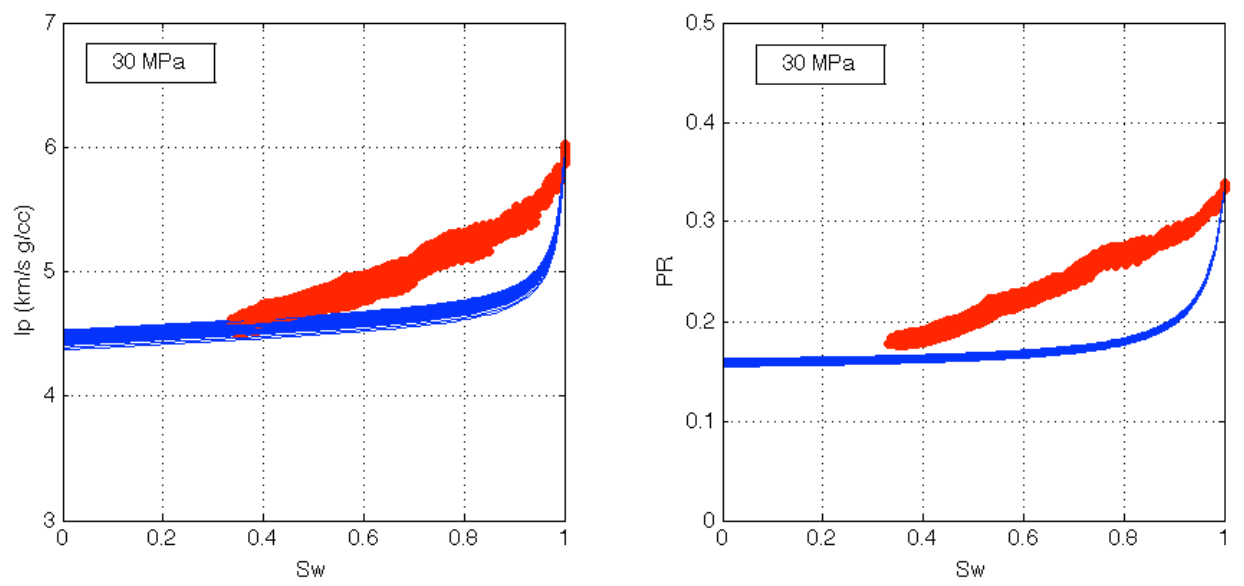

Figure 2.8. Same as Figure 2.7 but for $30 \mathrm{MPa}$ confining stress.

Arguably, CPET gives us a better insight into the change of the elastic properties 
during replacement of water by gas than ad-hoc assumptions about fluid distribution in the rock, uniform or patchy (see discussion about fluid distribution in, e.g., Mavko et al., 2009). Hence, it may be instrumental in interpreting the seismic amplitude for $\mathrm{CO}_{2}$ saturation.

Figure 2.9 compares CPET predictions of elastic properties versus water saturation at two different confining stress levels, 15 and $30 \mathrm{MPa}$. In the field, low confining stress data correspond to high pore pressure (the elastic properties of rock depend on the differential stress, the difference between the overburden, which is constant and the pore pressure which is variable) while high confining stress data correspond to low pore pressure.
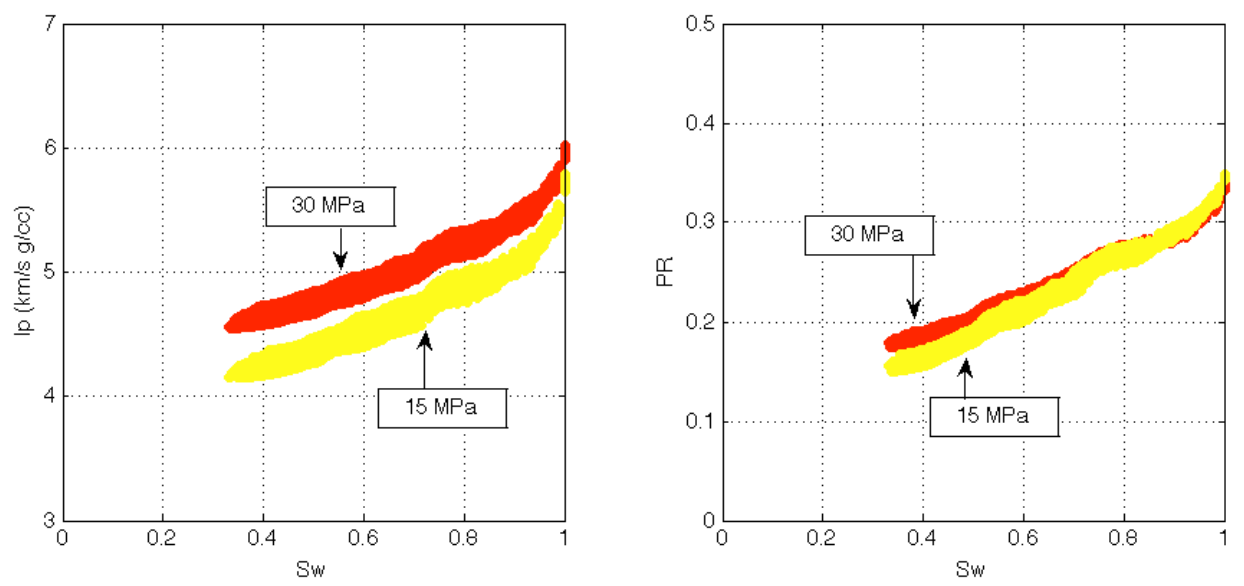

Figure 2.9. CPET results from Figures 2.7 and 2.8 for 15 and $30 \mathrm{MPa}$ confining stress.

In summary, CPET indicates that the elastic properties of rock strongly vary with varying saturation, while the traditional (Gassmann's) fluid substitution theory predicts little change almost in the entire saturation range with abrupt increase in $I_{p}$ and $v$ occurring only at extremely high water saturation, in excess of $90 \%$.

For further illustration of this effect consider Figure 2.10 where we plot $I_{p}$ versus $v$ according to CPET (red) and traditional fluid substitution (blue) for both 15 and $30 \mathrm{MPa}$ confining stress. CPET produces gradual transition from low-impedance low-Poisson's ratio at low water saturation to high-impedance high-Poisson's ratio at $100 \%$ water saturation. In contrast, traditional fluid substitution predict abrupt changes between these two endpoints. This effect is better seen in Figure 2.10 (right), where the elastic property 
symbols are color-coded by water saturation.
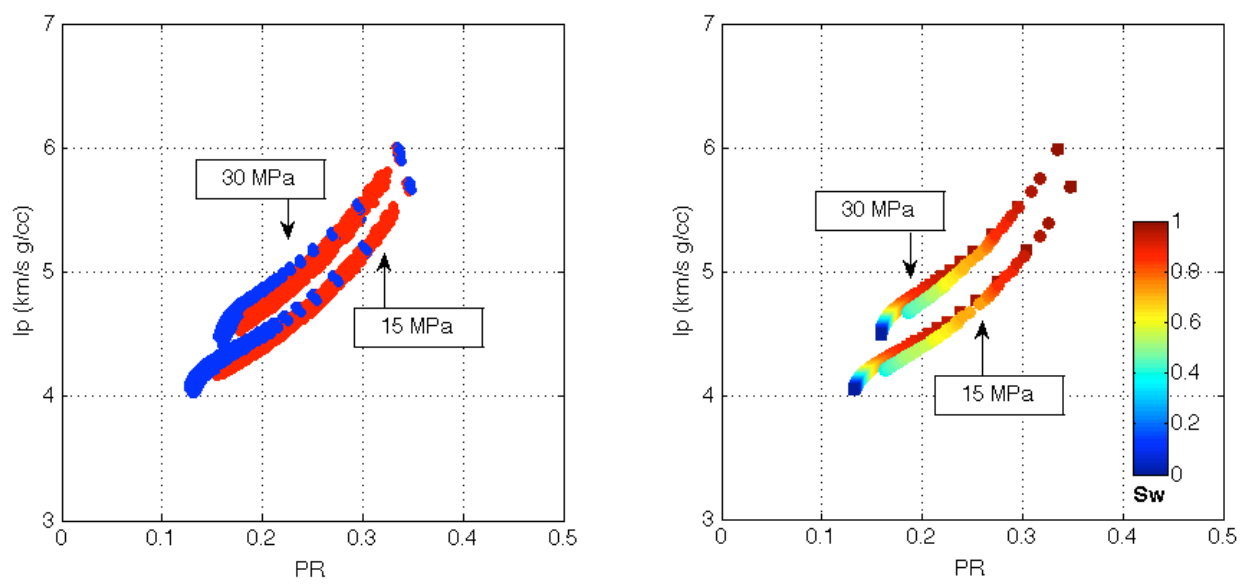

Figure 2.10. Left: Impedance versus Poisson's ratio as water saturation changes for 15 and $30 \mathrm{MPa}$ confining stress data according to CPET (red) and traditional fluid substitution (blue). Right: The same results but color-coded by water saturation (circles for CPET and squares for traditional fluid substitution).

Attenuation. CPET allows us not only to compute the elastic properties but also the P-wave attenuation. To approach this task, let us assume that CPET provides us with relatively high-frequency prediction while traditional fluid substitution is for lowfrequency data. The difference between these two predictions can be interpreted in terms of the inverse quality factor $Q^{-1}$ as (see Mavko et al., 2009)

$$
Q^{-1}=\frac{1}{2} \frac{M_{\infty}-M_{0}}{\sqrt{M_{\infty} M_{0}}},
$$

where $M_{0}$ is the compressional modulus at low frequency (presumably given by the traditional fluid substitution) while $M_{\infty}$ is the same modulus but at high frequency (presumably given by CPET). The $Q^{-1}$ results computed using the Troll data at 15 and $30 \mathrm{MPa}$ are shown in Figure 2.11. The attenuation reaches its peak at high water saturation (low CO2 saturation) that occurs just in the beginning of the drainage.

Effect of Permeability. Because the drainage process strongly depends on the threshold pressure $P_{t}$ which, in turn, depends on the permeability (Equation 2.2), it is instructive to explore the effect of permeability on the elastic properties and attenuation during $\mathrm{CO}_{2}$ injection. To address this question, we will first ad-hoc reduce the 
permeability of the Troll samples by a factor of 10 . The resulting impedance and Poisson's ratio are shown in Figure 2.12. The CPET results for this case fall on those for the original permeability data except that the computed data in this case start at higher water saturation. This is a result of increasing irreducible water saturation due to reduced permeability.
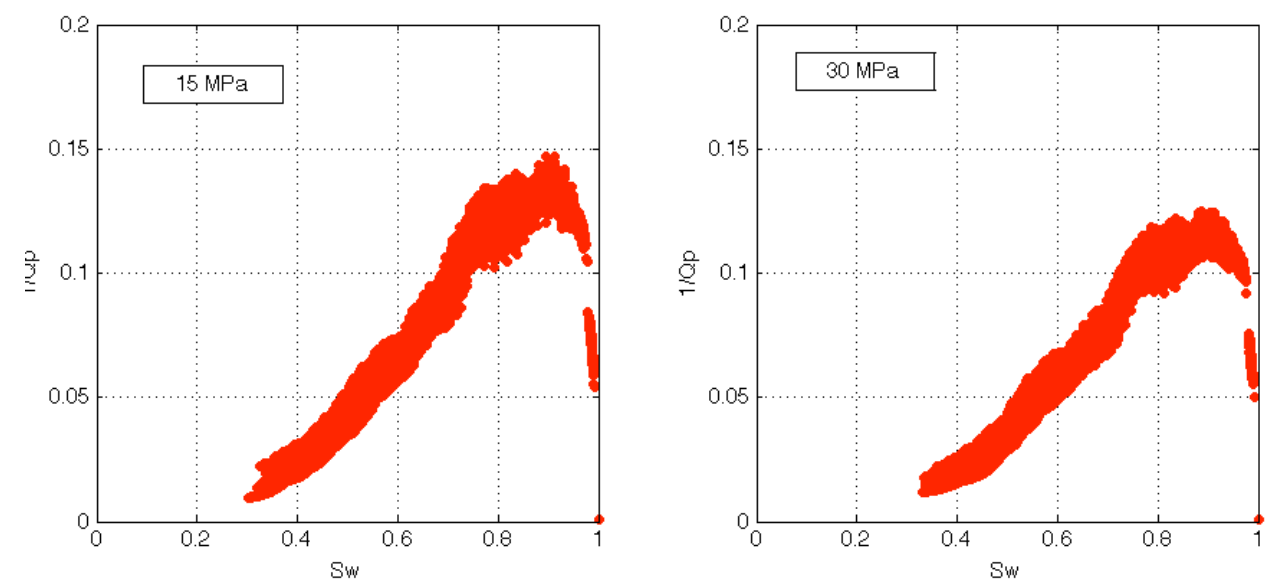

Figure 2.11. The inverse quality factor computed according to CPET and using the Troll data at 15 MPa (left) and $30 \mathrm{MPa}$ confining stress (right).
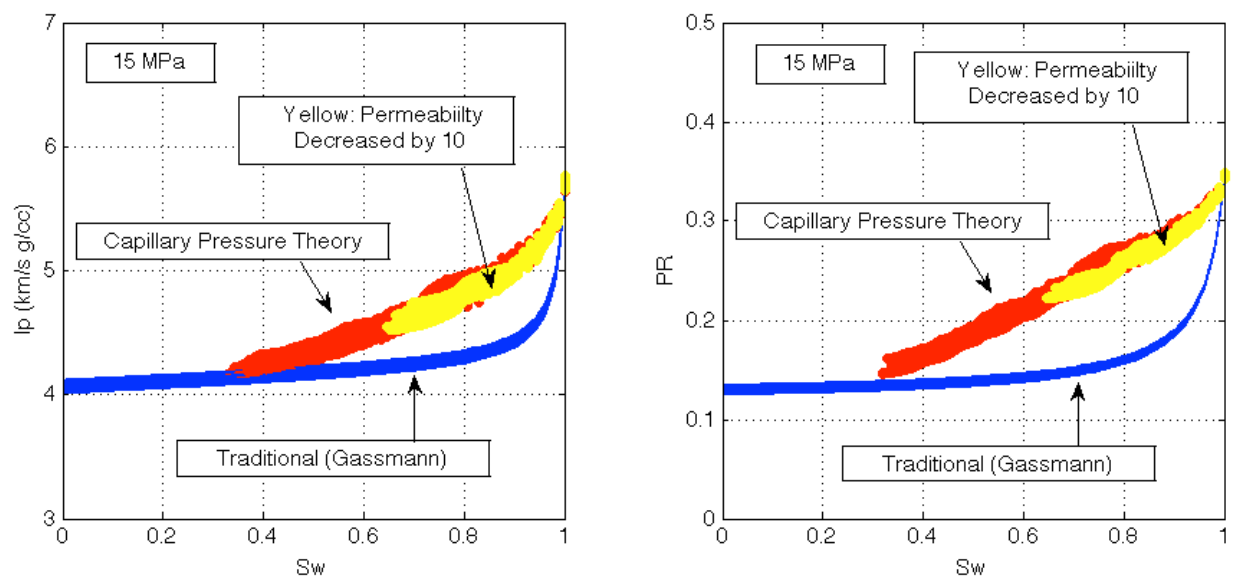

Figure 2.12. Same as Figure 2.7 but for the permeability reduced by a factor of 10 (yellow). Red symbols are for the original case (Figure 2.7). The Gassmann fluid substitution results remain unchanged.

Figure 2.13 shows the results for the case where the permeability of the Troll samples is ad-hoc increased by a factor of 10 . The computed impedance and Poisson's ratio versus saturation data fall on the same trend but start at lower water saturation simply 
because the irreducible water saturation decreases with increasing permeability.
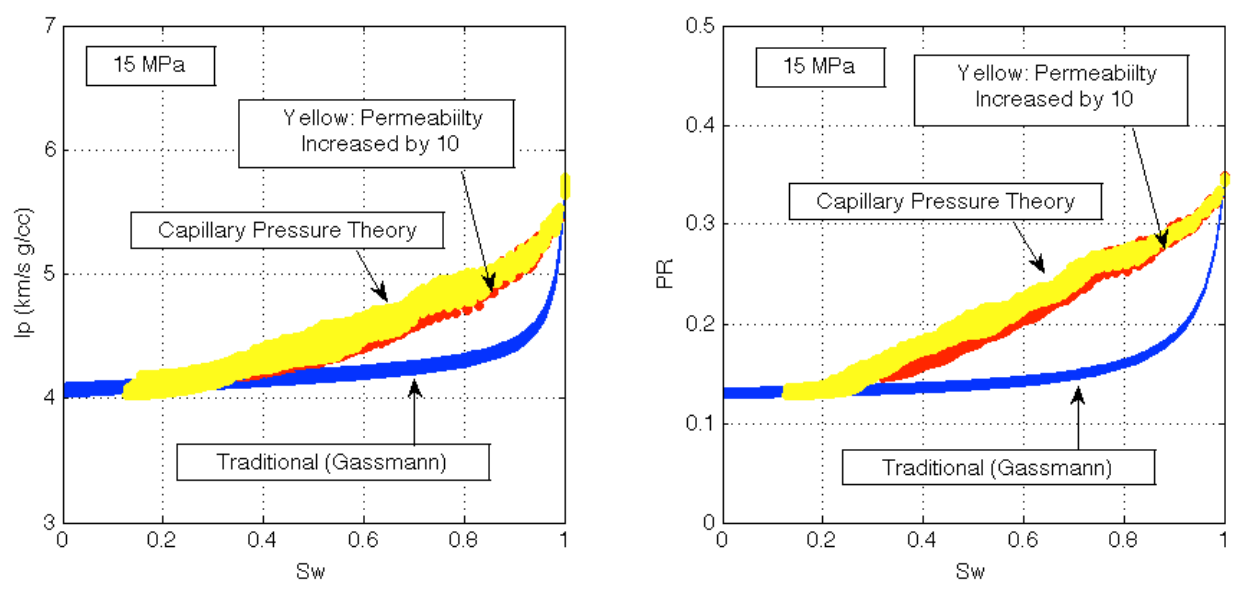

Figure 2.13. Same as Figure 2.12 but for the permeability increased by a factor of 10 (yellow). 


\section{Synthetic Seismic Signatures}

Reflection Modeling at an Interface. Forward modeling of seismic reflections at an interface between two elastic half-spaces is a traditional way of setting expectations for the character of seismic traces between the overburden shale and sand reservoir; at gas-

oil, gas-water, and oil/water contacts; as well as at various unconformities present in the subsurface. To conduct such computations, the elastic properties of both half-spaces are required. If we know the site-specific transforms between the rock properties and conditions and the elastic properties, we can compute seismic reflections at an interface as a function of porosity, lithology, and fluid. Here we will explore the reflections at the interface between a shale seal and soft sandstone reservoir, host to $\mathrm{CO}_{2}$ sequestration. As before, the model for the reservoir will come from the Troll data whereas the elastic properties of the shale will be computed using the soft sediment rock physics model (Mavko et al., 2009) and assuming the porosity of the shale 25\% and its clay content 75\%. This shale will be fully brine saturated (the properties of the brine are the same as used in the previous section).

Normal Reflectivity and Reflectivity at an Angle. The reflectivity at an interface between two elastic bodies is defined as the ratio of the reflected wave amplitude to the incident wave amplitude. As the wave strikes the interface, it produces the reflected and transmitted waves (Figure 3.1). Here we will analyze only the reflected $P$-wave. The incident $P$-wave can approach the interface in the direction normal to the interface or at a non-zero angle (Figure 3.1). The angle of incidence is defined as the angle between the direction of propagation of the wave front and the direction normal to the interface between the two half-spaces. While a normal $P$-wave does not produce $S$-waves, a $P$ wave at a non-zero incident angle produces reflected and transmitted $S$-waves. In the following equations for the $P$-to- $P$ reflectivity, the properties of the upper interface are marked by subscript “ 1 ” while those of the lower interface are marked by subscript " 2. "

The equation for the amplitude of the reflected $P$-wave is especially simple for normal incidence (Zoeppritz, 1919 - see the equations in Mavko et al., 2009):

$$
R_{p p}(0)=\frac{\rho_{2} V_{p 2}-\rho_{1} V_{p 1}}{\rho_{2} V_{p 2}+\rho_{1} V_{p 1}}=\frac{I_{p 2}-I_{p 1}}{I_{p 2}+I_{p 1}} \approx \frac{1}{2} \ln \frac{I_{p 2}}{I_{p 1}},
$$


where $R_{p p}(0)$ is the normal-incidence $P$-to- $P$ reflectivity (zero angle of incidence). Equation 3.1 indicates that the normal reflectivity only depends on the impedances of the half-spaces.
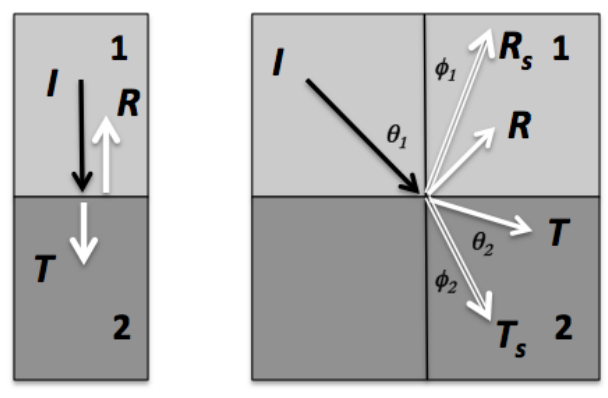

Figure 3.1. Left: $P$-wave normal to the interface $(I)$ and the reflected $(R)$ and transmitted $(T) P$-waves. Right: $P$-wave at a non-zero angle of incidence. $\theta_{1}$ is the angle of incidence while $\theta_{2}$ is the angle of the transmitted wave. The upper elastic half-space is marked by number " 1 " while the lower halfspace is marked by number " 2 ." The reflected and transmitted $S$-waves are marked " $R_{s}$ ” and " $T_{s}$," respectively. The angles of the reflected and transmitted $S$-waves are $\theta_{1}$ and $\theta_{2}$, respectively.

The angle of the reflected $P$-wave is the same as the angle $\theta_{1}$ of the incident $P$-wave. The angle $\theta_{2}$ of the transmitted $P$-wave is determined from the following equation:

$$
\sin \theta_{2}=\sin \theta_{1} \frac{V_{p 2}}{V_{p 1}}
$$

The equation for the amplitude of the reflected $P$-wave at a non-zero angle of incidence $\theta_{1}$ is fairly complicated (Zoeppritz, 1919; Aki and Richards, 1980 - see the equations in Mavko et al., 2009):

$$
R_{p p}\left(\theta_{1}\right)=\left[\left(b \frac{\cos \theta_{1}}{V_{p 1}}-c \frac{\cos \theta_{2}}{V_{p 2}}\right) F-\left(a+d \frac{\cos \theta_{1}}{V_{p 1}} \frac{\cos \phi_{2}}{V_{s 2}}\right) H p^{2}\right] / D,
$$

where angle $\phi_{2}$ is that of the transmitted $S$-wave (Figure 3.1). This angle $\phi_{2}$ as well as the angle $\phi_{1}$ of the reflected $S$-wave and the ray parameter $p$ are determined from the following equation:

$$
p=\frac{\sin \theta_{1}}{V_{p 1}}=\frac{\sin \theta_{2}}{V_{p 2}}=\frac{\sin \phi_{1}}{V_{s 1}}=\frac{\sin \phi_{2}}{V_{s 2}} .
$$

The other parameters in Equation 3.3 are: 


$$
\begin{aligned}
& a=\rho_{2}\left(1-2 \sin ^{2} \phi_{2}\right)-\rho_{1}\left(1-2 \sin ^{2} \phi_{1}\right) \quad b=\rho_{2}\left(1-2 \sin ^{2} \phi_{2}\right)+2 \rho_{1} \sin ^{2} \phi_{1} ; \\
& c=\rho_{1}\left(1-2 \sin ^{2} \phi_{1}\right)+2 \rho_{2} \sin ^{2} \phi_{2} ; \quad d=2\left(\rho_{2} V_{s 2}^{2}-\rho_{1} V_{s 1}^{2}\right) \\
& D=E F+G H p^{2} ; \\
& E=b \frac{\cos \theta_{1}}{V_{p 1}}+c \frac{\cos \theta_{2}}{V_{p 2}} ; \quad F=b \frac{\cos \phi_{1}}{V_{s 1}}+c \frac{\cos \phi_{2}}{V_{s 2}} ; \\
& G=a-d \frac{\cos \theta_{1}}{V_{p 1}} \frac{\cos \phi_{2}}{V_{s 2}} ; \quad H=a-d \frac{\cos \theta_{2}}{V_{p 2}} \frac{\cos \phi_{1}}{V_{s 1}}
\end{aligned}
$$

The curves that plot $R_{p p}(\theta)$ versus the angle of incidence $\theta$ are called the amplitude versus offset or simply AVO curves (more precisely, the amplitude versus angle or AVA curves).

Numerous approximations to the Zoeppritz (1919) reflectivity equation have been introduced over the years (Castagna et al., 1993). They are usually called AVO approximations. Arguably, the simplest and a very convenient one is by Hilterman (1989):

$$
\begin{aligned}
& R_{p p}(\theta) \approx R_{p p}(0) \cos ^{2} \theta+2.25 \Delta v \sin ^{2} \theta=R_{p p}(0)+2.25\left[\Delta v-R_{p p}(0)\right] \sin ^{2} \theta \\
& R_{p p}(0)=\left(I_{p 2}-I_{p 1}\right) /\left(I_{p 2}+I_{p 1}\right),
\end{aligned}
$$

where $\Delta v=v_{2}-v_{1}$ is the difference between the Poisson's ratio $v_{2}$ of the lower halfspace and that $\left(v_{1}\right)$ of the upper half-space. Although approximate, Equation 3.6 produces the reflectivity close to that produced by the exact Equation 3.3 where the incidence angle is not large and the elastic contrast between the elastic half-spaces is small.

Because many AVO approximations employ the form where $R_{p p}(\theta)$ is a function of $\sin ^{2} \theta$ :

$$
R_{p p}(\theta)=R+G \sin ^{2} \theta
$$

the two parameters commonly used to describe the character of an AVO curve are the intercept $R$ and gradient $G$. For the Hilterman (1989) AVO approximation,

$$
R=R_{p p}(0), \quad G=2.25\left[\Delta v-R_{p p}(0)\right]
$$

No matter whether the exact AVO equation is used or any of its approximate forms, 
the intercept is always

$$
R=R_{p p}(0)=\left(I_{p 2}-I_{p 1}\right) /\left(I_{p 2}+I_{p 1}\right) \approx 0.5 \ln \left(I_{p 2} / I_{p 1}\right) .
$$

Forward Modeling Using Elastic Constants. Because Equation 3.6 uses only two elastic parameters, the P-wave impedance and Poisson's ratio, is especially convenient for the purpose of displaying the effect of the elastic constants on the AVO curve. An example of such display is shown in Figure 3.1 where in the $I_{p}$ versus $v$ plane we first select the $I_{p}-v$ pair for the upper half-space (the symbol on the right) and then for the lower half-space (the symbol on the left). From this two pairs and using Equation 3.6, $R_{p p}(\theta)$ is computed as a function of the incident angle and the intercept and gradient are determined from Equation 3.8. Next, the resulting seismic gather is computed by convolving the Ricker wavelet with reflectivity determined at the interface at each incidence angle and displayed in a separate window.
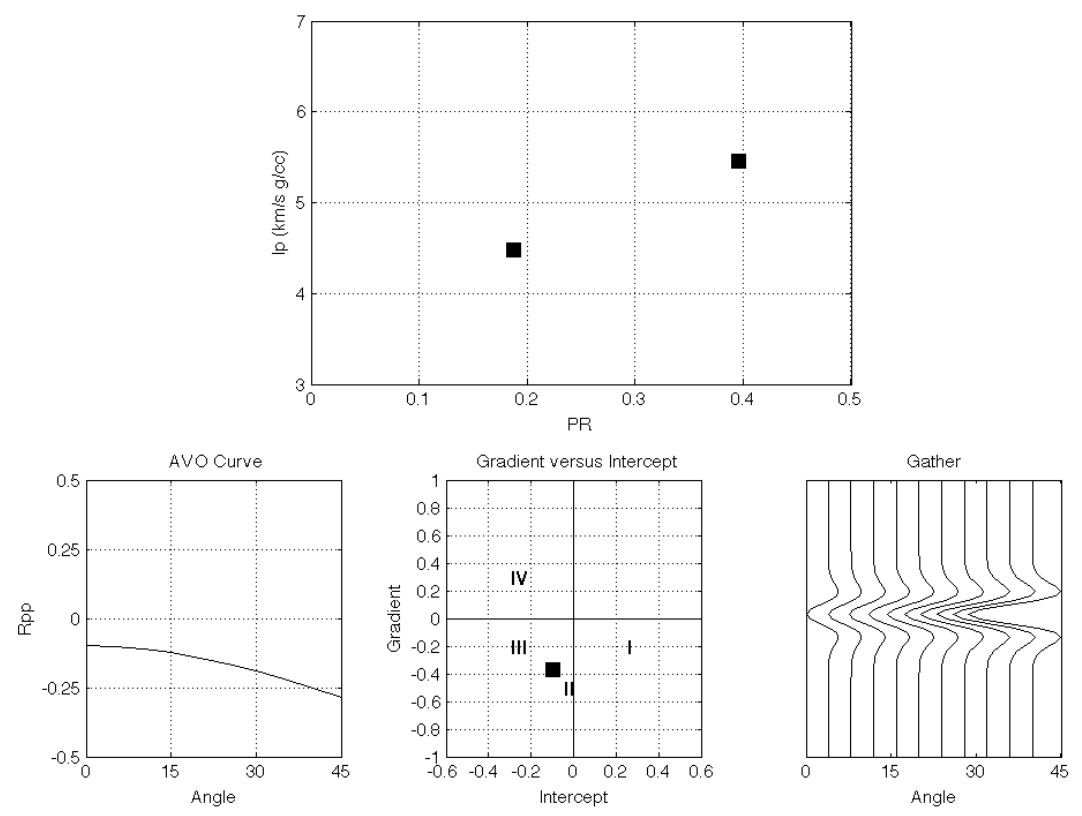

Figure 3.2. Elastic AVO modeling. Top: P-wave impedance versus Poisson's ratio. Two points in this graph are selected, the first one for the upper half-space (on the right in this example) and the second one for the lower half-space (on the left). Bottom, from left to right: The AVO curve; gradient versus intercept with AVO class (I to IV) marked in the quadrants; and the seismic gather where the reflected wave traces are plotted versus the angle of incidence. The vertical axis in the gather plot is TWT (two-way travel time) or depth. 
Forward Modeling for $\mathrm{CO}_{2}$ Injection. The same modeling principle can be used to forecast the seismic signatures during $\mathrm{CO}_{2}$ sequestration. The display shown in Figure 3.2 can be used where the actual physics-based domains of the impedance and Poisson's ratio are outlined in the top panel (Figure 3.3).

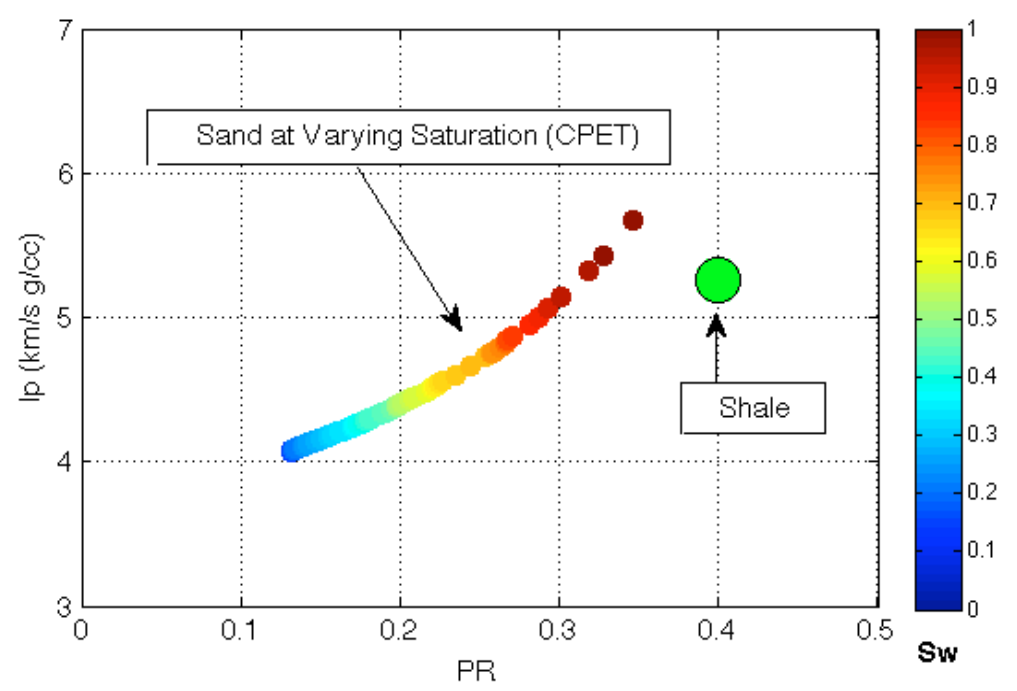

Figure 3.3. The top panel from Figure 3.2 with the impedance versus Poisson's ratio domains shown for the shale (green circle) and Troll sand at varying water saturation (see colorbar).

The synthetic seismic examples can be now forward-modeled using the same principle as depicted in Figure 3.2 but selecting the e $I_{p}-v$ points according to the capillary pressure equilibrium theory (Figure 3.4 to 3.8 ).

These examples indicate that at $\mathrm{CO}_{2}$ saturation increases, both the P-wave impedance and Poisson's ratio in the sand gradually decrease. As a result, the AVO response moves from weak Class I to Class II and to increasingly strong Class III.

This gradual change in the seismic response versus $\mathrm{CO}_{2}$ saturation is quite different from that predicted by the traditional (Gassmann's) fluid substitution where an abrupt change between the reflection of a $100 \%$ saturated saline reservoir and that at the same reservoir but with only small quantities of gas is abrupt. In the latter case, it may be impossible, indeed, to quantify $\mathrm{CO}_{2}$ saturation from the seismic amplitude (Figure 3.9 3.11). In contrast, if the capillary pressure equilibrium theory at least approximately describes the elastic-property variations in the reservoir during sequestration, it may be plausible to track and quantify gas saturation in space and time. 

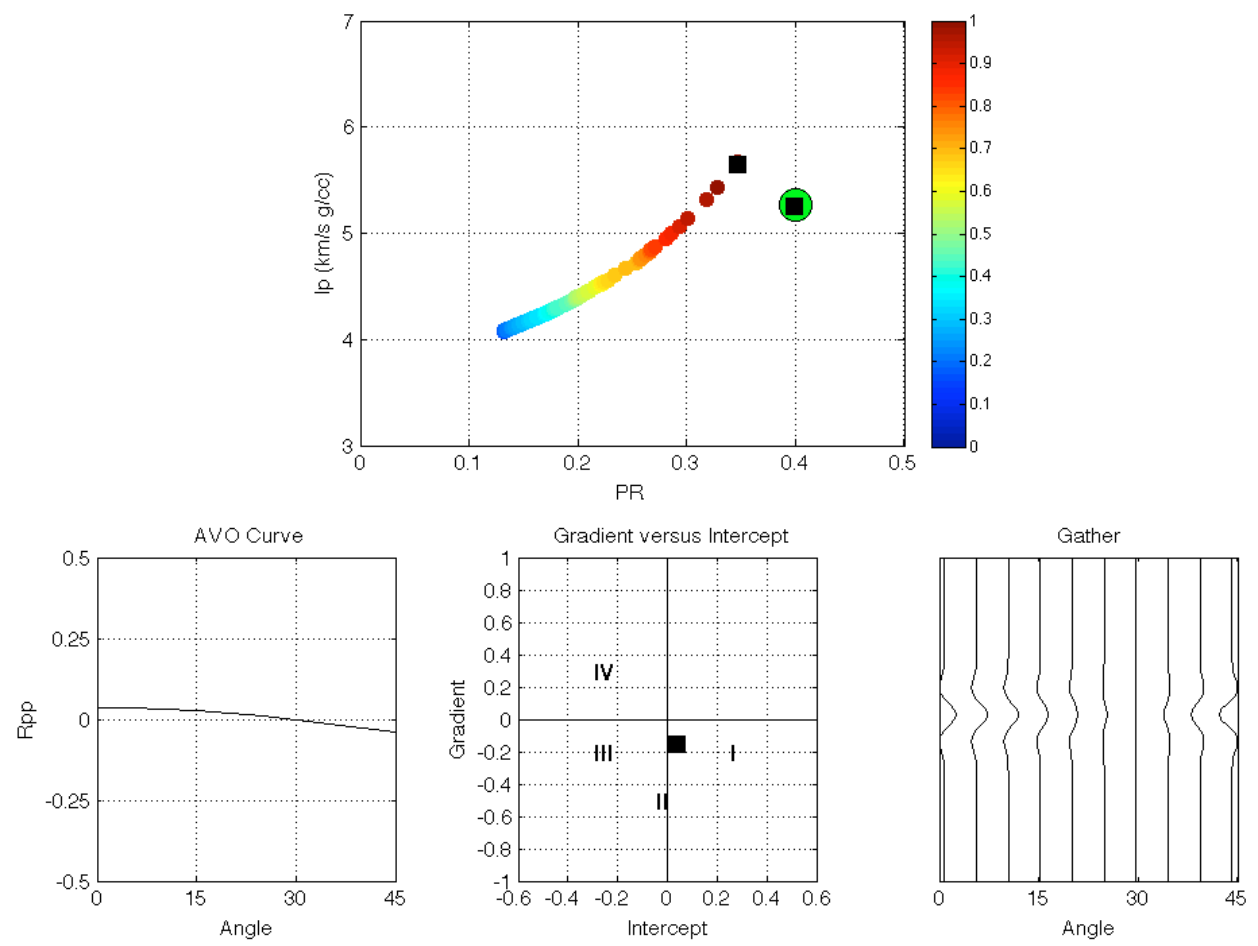

Figure 3.4. Synthetic reflection between shale and wet sandstone reservoir.
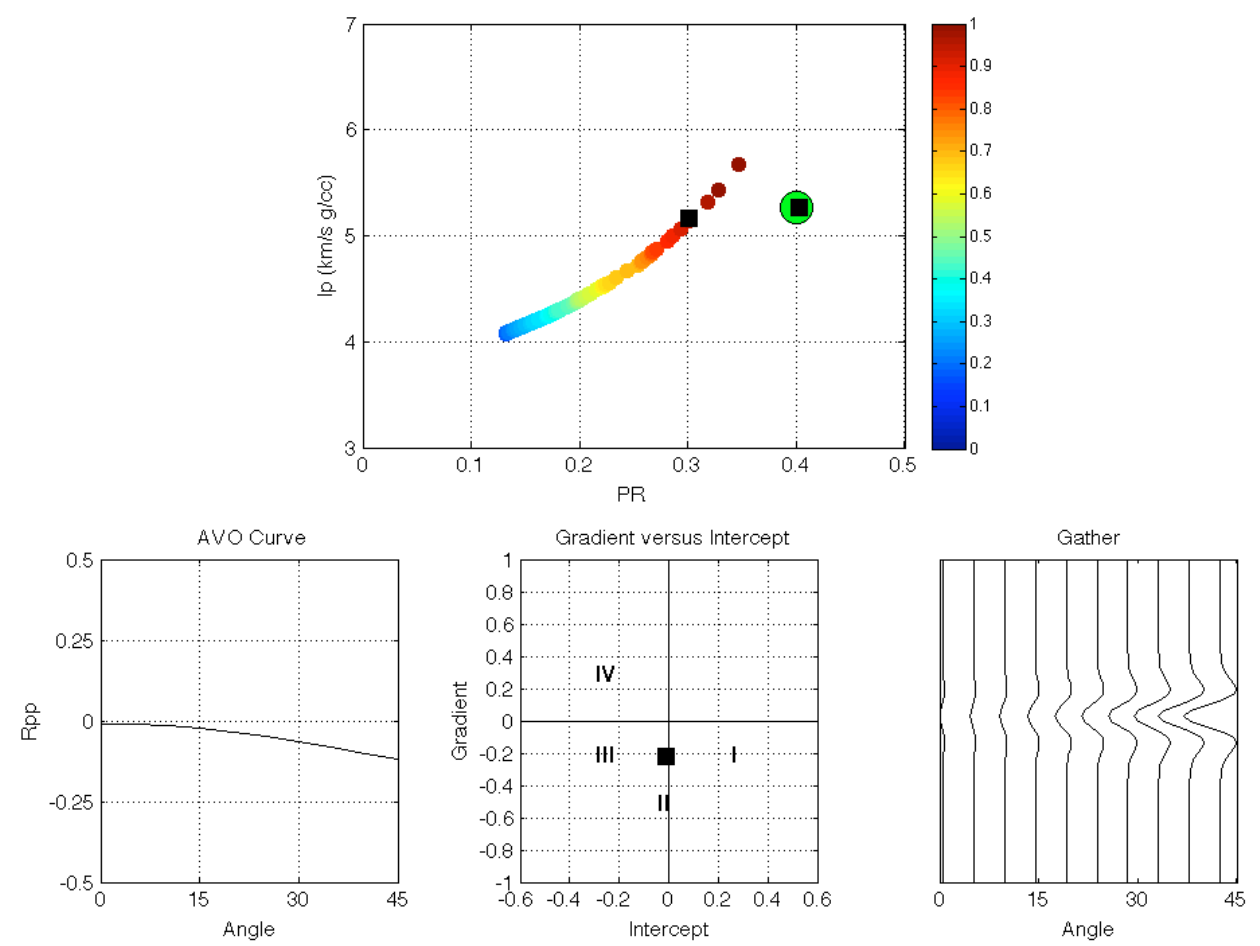

Figure 3.5. Same as Figure 3.4 but at high water saturation (low gas saturation). 

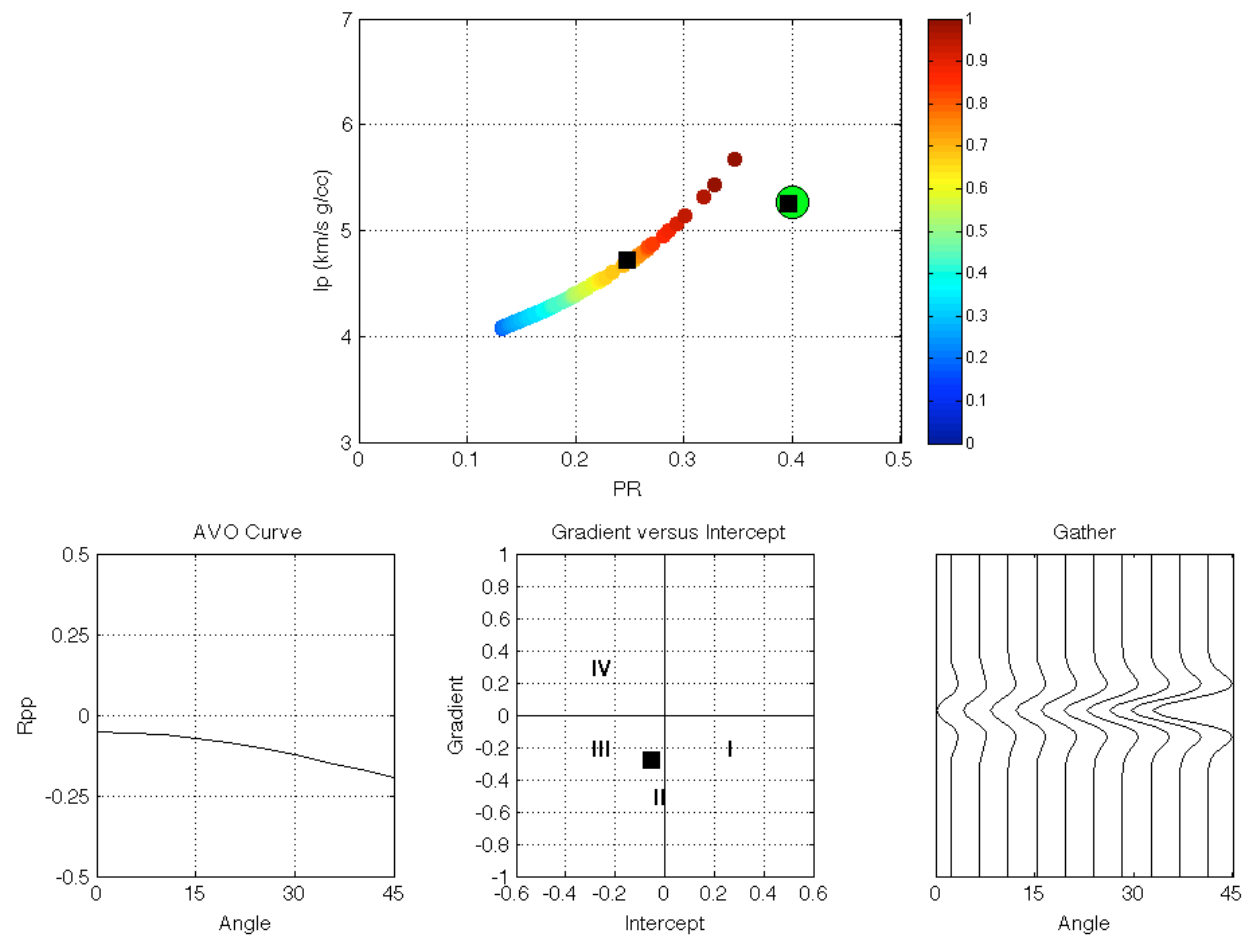

Figure 3.6. Same as Figure 3.5 but at decreasing water saturation (increasing gas saturation).
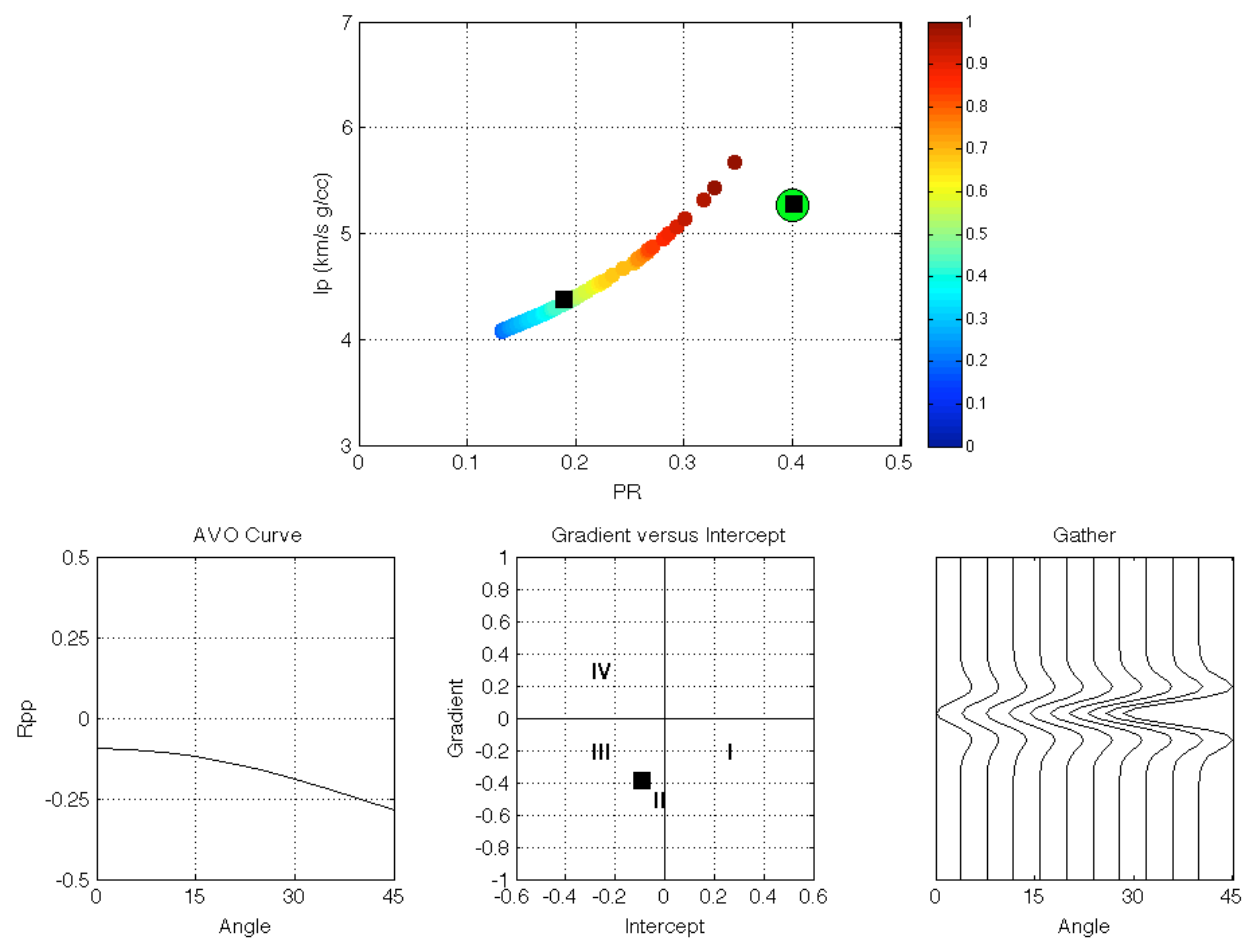

Figure 3.7. Same as Figure 3.6 but at decreasing water saturation (increasing gas saturation). 

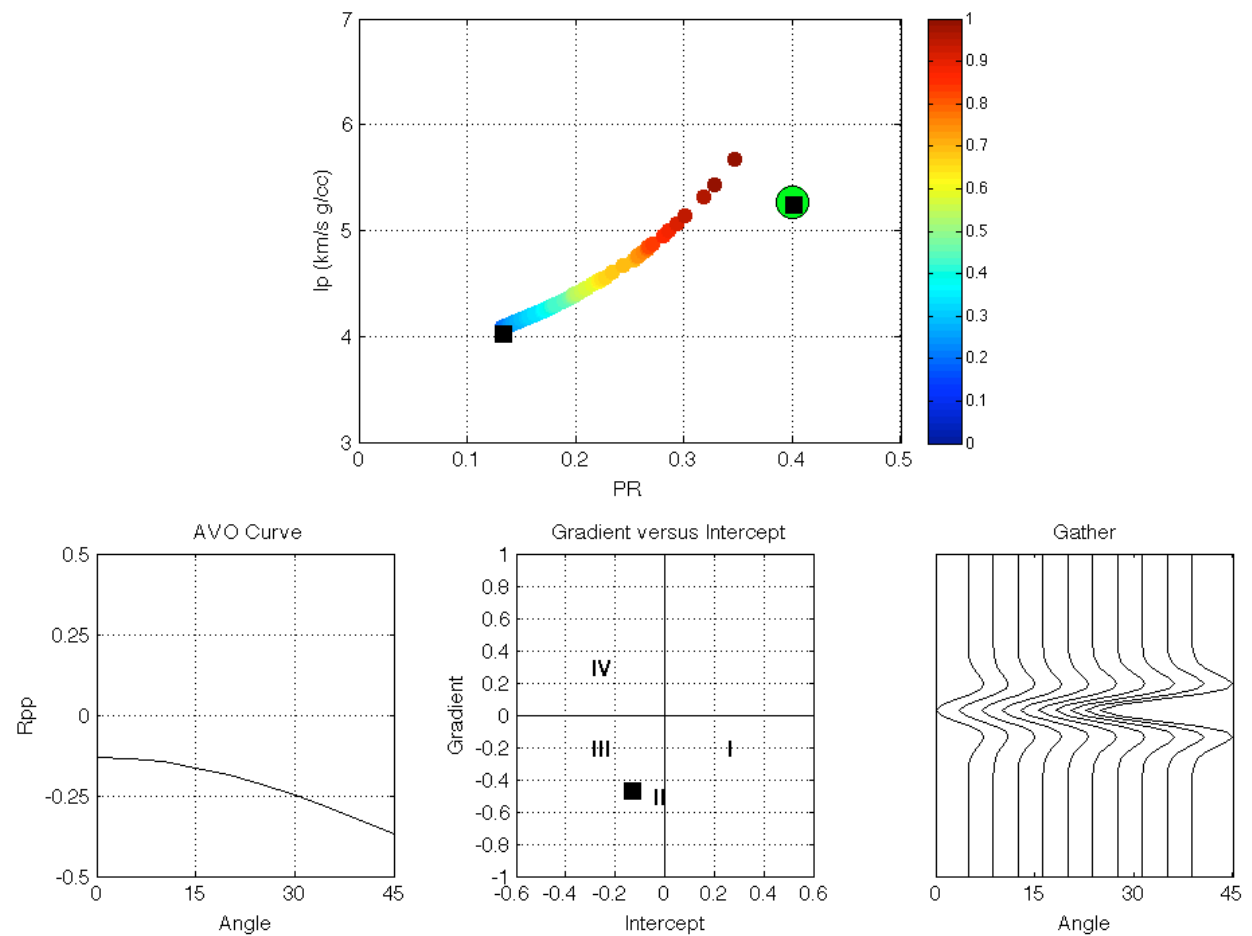

Figure 3.8. Same as Figure 3.7 but at low water saturation (high gas saturation).
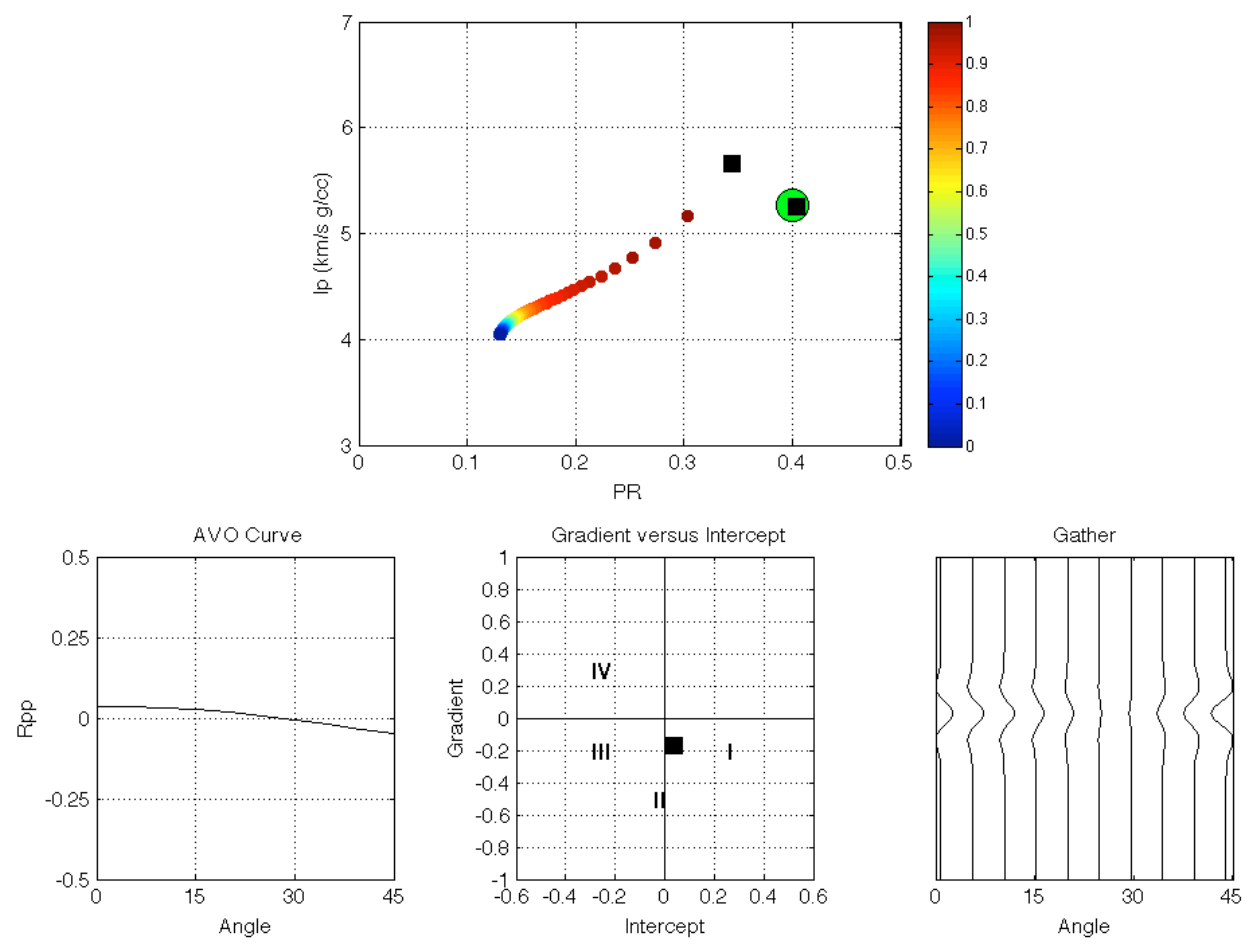

Figure 3.9. Same as Figure 3.4 but using Gassmann's fluid substitution instead of CPET. 

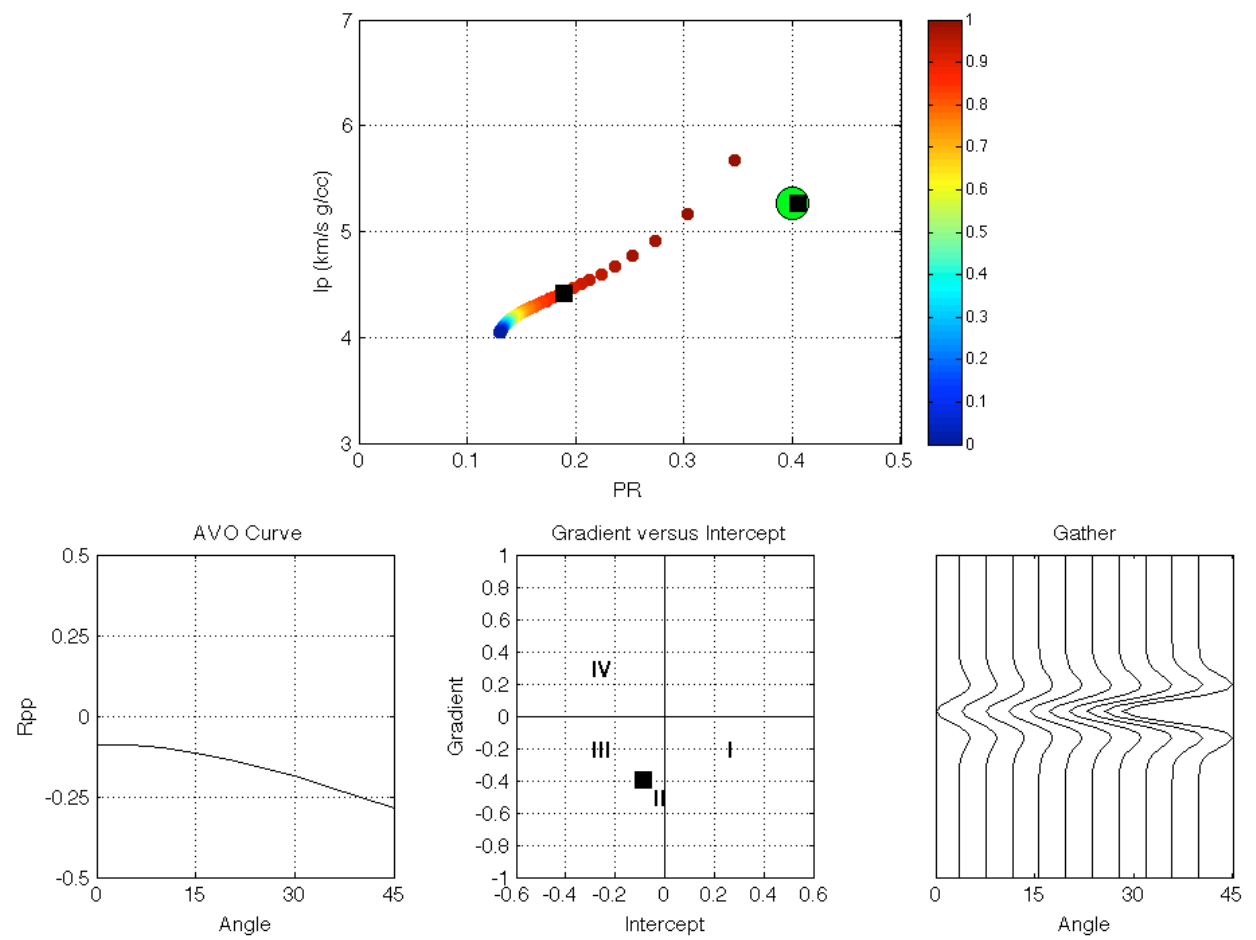

Figure 3.10. Same as Figure 3.9 (Gassmann's fluid substitution instead of CPET) at low gas saturation.
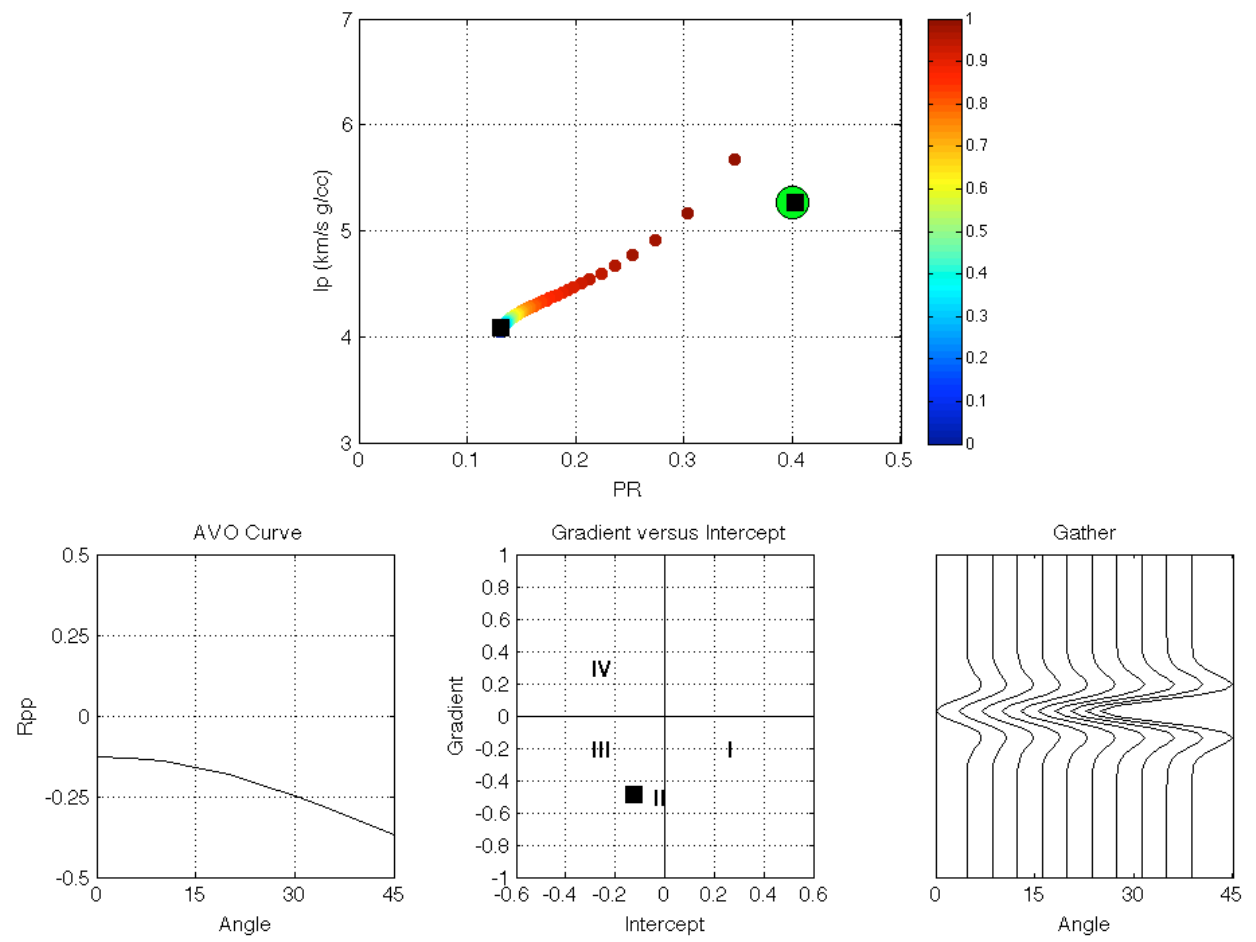

Figure 3.11. Same as Figure 3.10 but at high gas saturation. 


\section{Practical Fluid Substitution on Well Data}

Decomposing a Datum: Heterogenezation. How to apply CPET to well log data where each datum along the wellbore depth covers about $0.3 \mathrm{~m}$ interval? In other words, how to conduct CPET-based fluid substitution on a datum? To do this, we need to decompose an apparently homogeneous volume of rock into subsamples.

Assume, for example that we have log-derived porosity $\left(\phi_{0}\right)$ and clay content $\left(C_{0}\right)$ values at a point in depth. Assume also that we know a rock physics model that relates porosity and clay content to the elastic properties and density of rock in this depositional system as well as a site-specific porosity-clay-permeability relation. These relations can be theoretical and/or empirical.

Let us assume next that the sample whose properties are measured is heterogeneous and inside this sample, the porosity $\phi$ of the subsamples can randomly vary between $\phi-\Delta \phi$ and $\phi+\Delta \phi$. The probability distribution of $\phi$ can have any desired shape. Here, for simplicity, we assume that this distribution is uniform. If the assumed number of the subsamples in this new composite is $n$, we will randomly draw $n$ samples from the interval $[\phi-\Delta \phi, \phi+\Delta \phi]$. Examples of such realizations are shown in Figure 4.1.
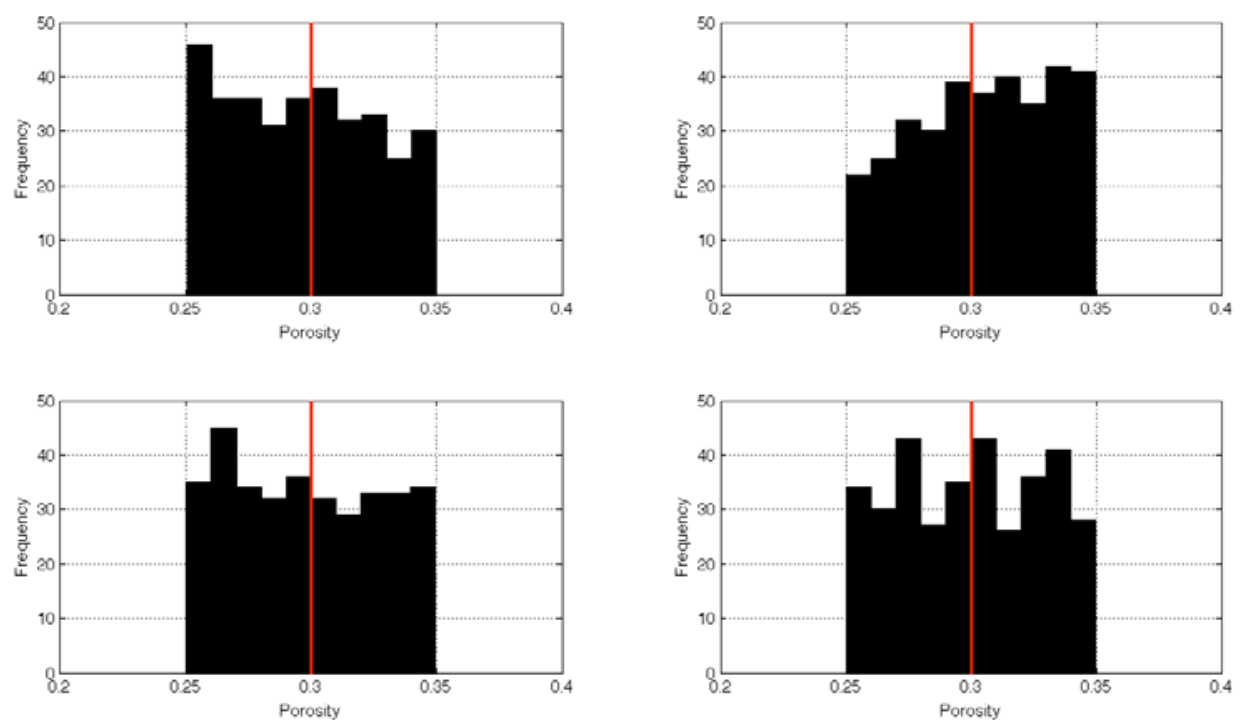

Figure 4.1. Histograms of four porosity subsample realizations for a sample with porosity 0.30 subdivided into $343=7^{3}$ subsamples whose porosity can vary within the 0.25 to 0.35 interval. 
The same method can be used to populate the subsamples with the clay content values. Here, for simplicity, we will assume that the clay content is the same for each subsample. As a result, the dry-rock elastic properties can be computed for each random porosity realization. In this example, we will use the soft-sand model (Mavko et al., 2009) that is appropriate for Troll-type reservoirs.

To assign permeability to each subsample we can use any appropriate empirical or theoretical equation. Here, let us take into account the fact that in soft clean sediment, porosity reduction is usually triggered by deteriorating sorting which means that the average grain size decreases with decreasing porosity. Let us also assume that such a relation between the grain size $d$ and porosity $\phi$ is linear and further assume that the end members of this relation are known, that is the grain size is $d_{\min }$ at porosity $\phi_{\min }$ and it is $d_{\max }$ at porosity $\phi_{\max }$. As a result, the grain size versus porosity relation is

$$
d=\frac{d_{\text {min }} \phi_{\max }-d_{\text {max }} \phi_{\min }}{\phi_{\max }-\phi_{\min }}+\frac{d_{\text {max }}-d_{\text {min }}}{\phi_{\text {max }}-\phi_{\min }} \phi .
$$

Finally, the absolute permeability $k$ can be related to porosity and grain size using the Kozeny-Carman equation (Equation 2.5) as

$$
k=d^{2} \frac{10^{9}}{72} \frac{\left(\phi-\phi_{p}\right)^{3}}{\left[1-\left(\phi-\phi_{p}\right)\right]^{2} \tau^{2}} .
$$

Assuming for simplicity that the percolation porosity $\phi_{p}$ is zero (which is appropriate for high-porosity sediment) we arrive at

$$
k=d^{2} \frac{10^{9}}{72} \frac{\phi^{3}}{(1-\phi)^{2} \tau^{2}},
$$

where the tortuosity $\tau$ for this example can be assumed constant.

Figure 4.2 shows an example of one porosity realization with the resulting velocityporosity and permeability-porosity cross-plots. In this specific example we assumed that the velocity-porosity relation is according to the soft sand model; the clay content is zero; $\phi_{\max }=0.35 ; \phi_{\min }=0.25 ; d_{\max }=0.20 \mathrm{~mm} ; d_{\min }=0.02 \mathrm{~mm} ;$ and $\tau=2.5$.

An example of fluid substitution for the datum with the global porosity 0.30 and zero clay content and using the described heterogenezation method are shown in Figure 4.3, 
where the display is the same as used in Figures 2.7 and 2.8.
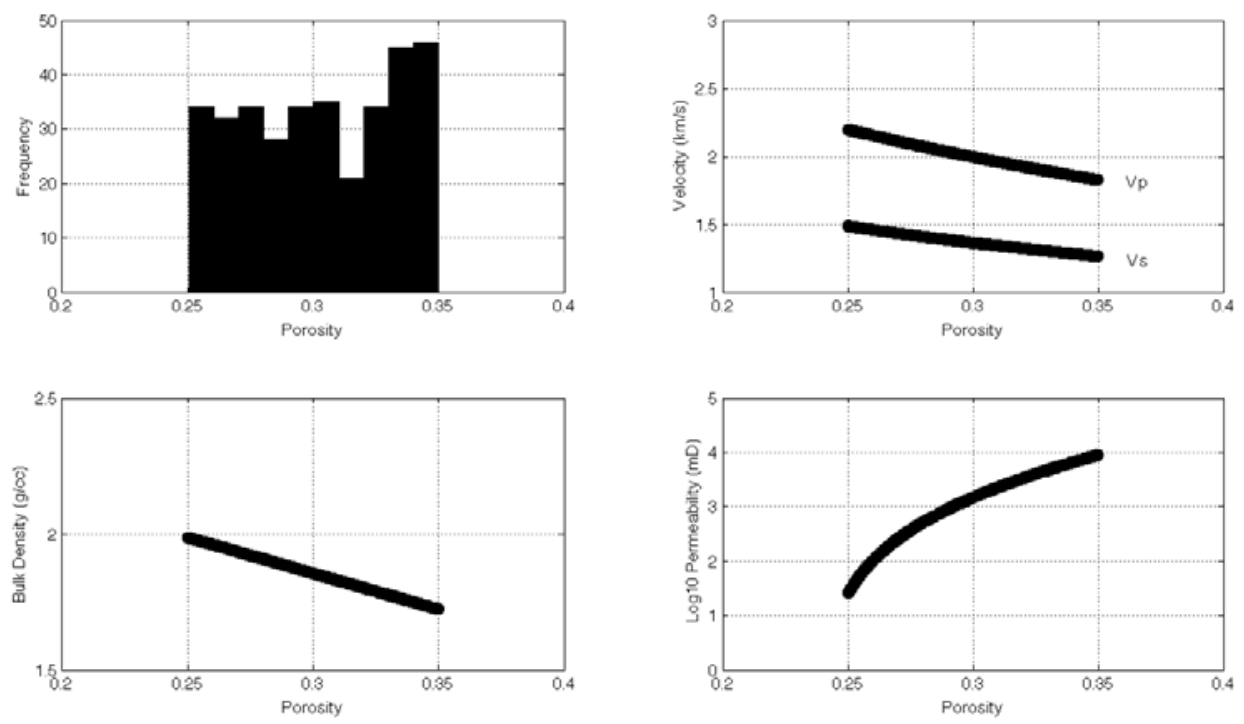

Figure 4.2. From left to right and top to bottom: Porosity histogram; dry-rock velocity versus porosity; dry-rock bulk density versus porosity; and permeability versus porosity.
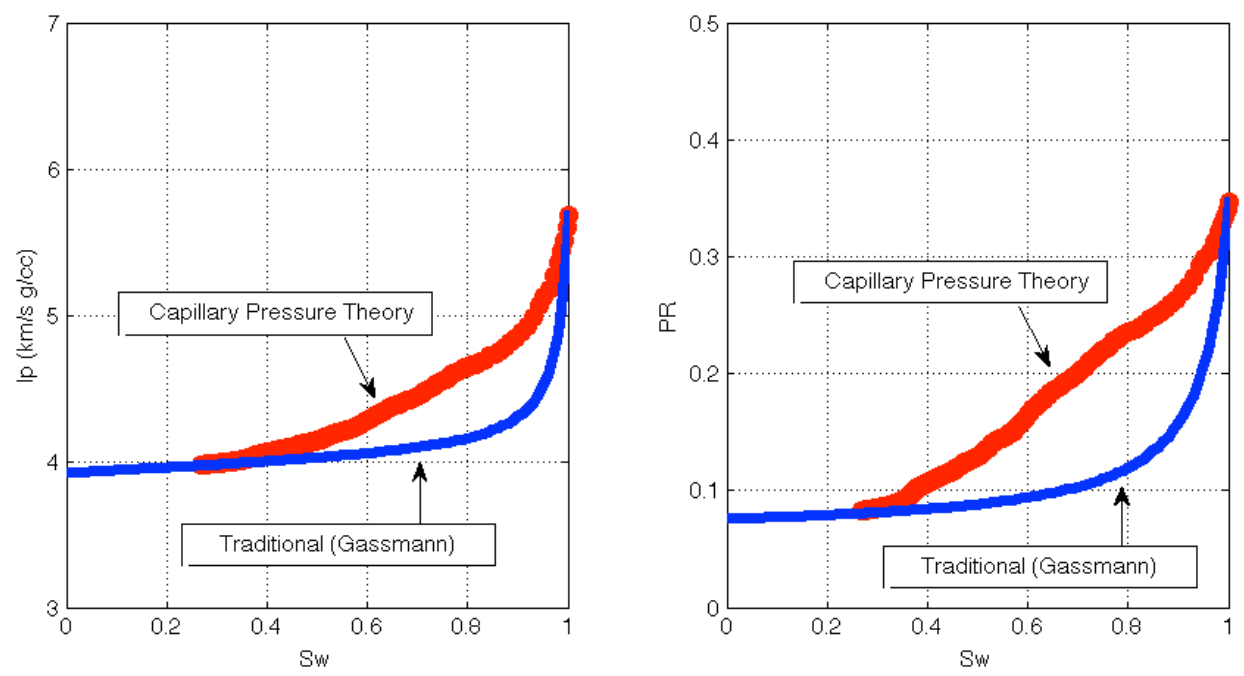

Figure 4.3. Impedance versus water saturation (left) and Poisson's ratio versus water saturation (right) resulting from fluid substitution conducted at a single point in the subsurface with porosity 0.30 and using the heterogenezation method describe here.

Fluid Substitution on Well Data. To illustrate this methodology of fluid substitution on well data, let us construct a synthetic log where a soft sand $100 \%$ brinesaturated interval is surrounded by shale. Figure 4.4 shows the rock properties and the 
resulting synthetic seismic gather in this pseudo-well.
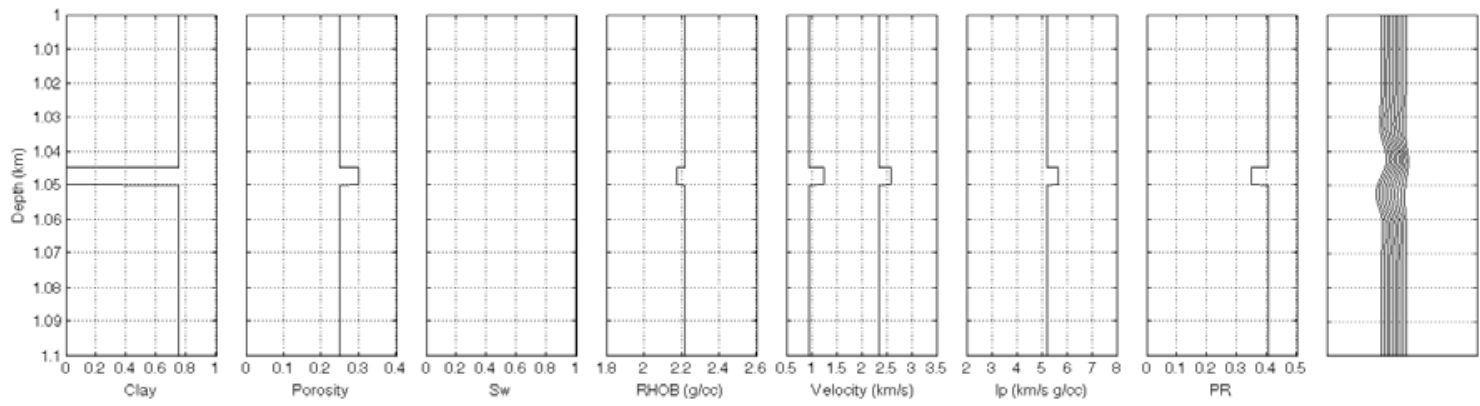

Figure 4.4. Pseudo-well where a wet sand interval is surrounded by shale. From left to right: Clay content; porosity; water saturation; bulk density; P- and S-wave velocity; P-wave impedance; Poisson's ratio; and the resulting synthetic seismic gather obtained using a ray tracer with a $40 \mathrm{~Hz}$ Ricker wavelet and maximum angle of incidence about $45^{\circ}$. The vertical axis in all plots is vertical depth in $\mathrm{km}$.

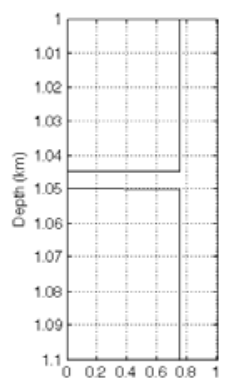

Clay
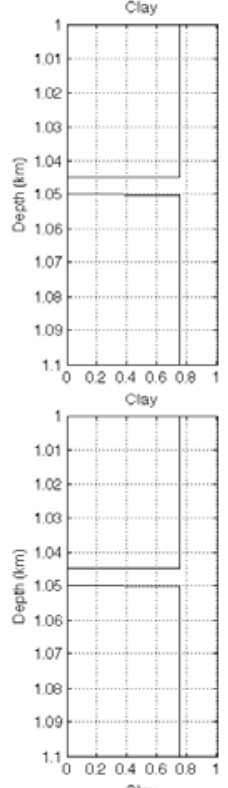

Clay
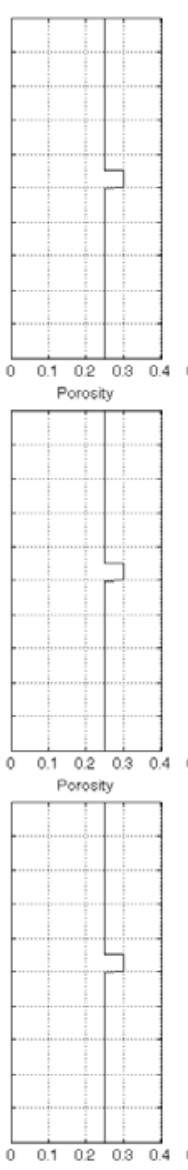

Porosity

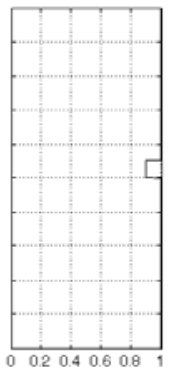

Sw
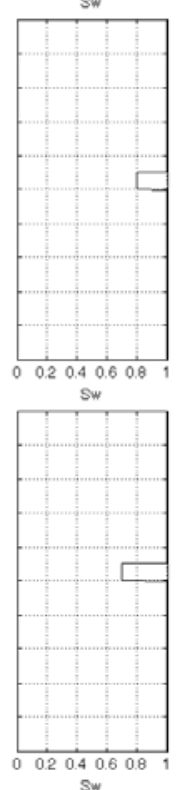
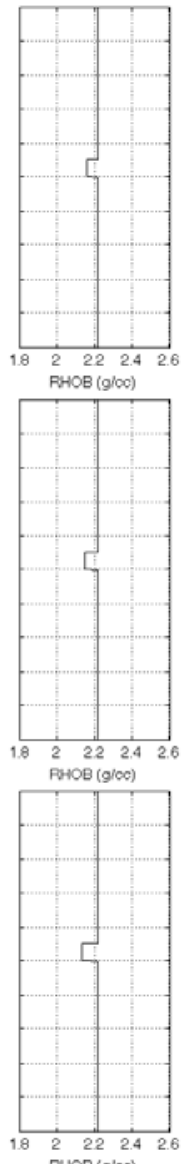
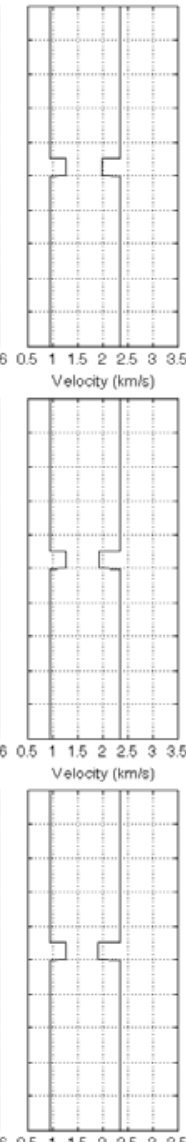

Velocity $(\mathrm{km} / \mathrm{s})$
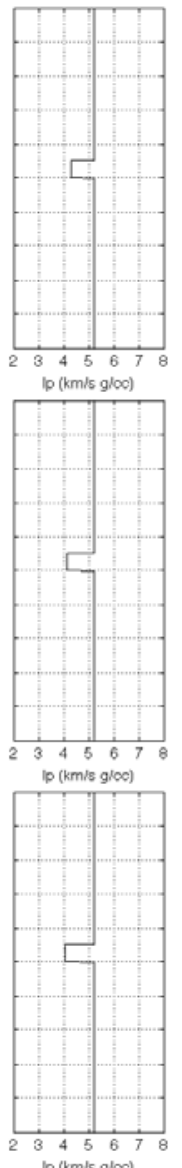

$10(\mathrm{~km} / \mathrm{s} g / \infty)$
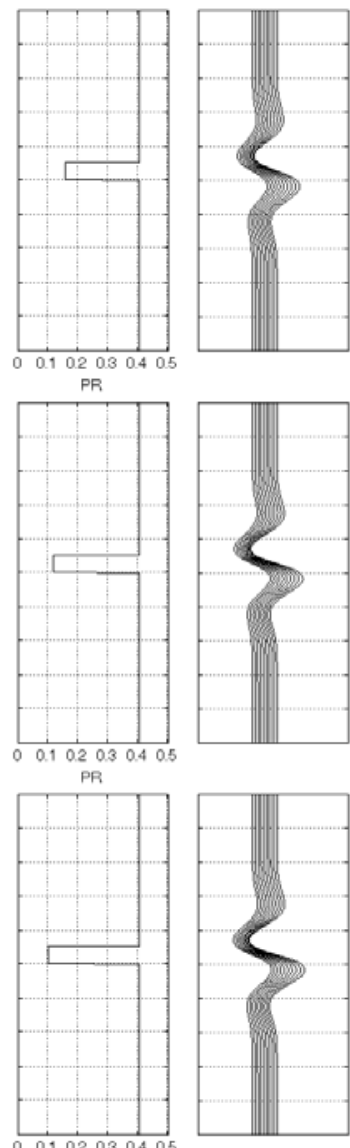

Figure 4.5. Same as Figure 4.4 but with gradually decreasing water saturation (increasing $\mathrm{CO}_{2}$ saturation) in the sand using the traditional (Gassmann's) fluid substitution. Gas saturation increases from 10 to 20 to $30 \%$ (top to bottom). 
Figure 4.5 shows how the rock properties and the resulting synthetic seismic gathers change as we gradually reduce water saturation from the original $100 \%$ to 90,80 , and $70 \%$ (the respective $\mathrm{CO}_{2}$ saturation increases from the original zero to 10,20 , and $30 \%$ ). The seismic response abruptly changes from that at zero gas saturation (Figure 4.4), which is weak AVO Class I, to strong Class III (Figure 4.5) as soon as only small amount of $\mathrm{CO}_{2}$ enters the system. Moreover, this response hardly varies as a function of gas saturation at low gas saturation (Figure 4.5) as well as at high gas saturation (Figure 4.6).
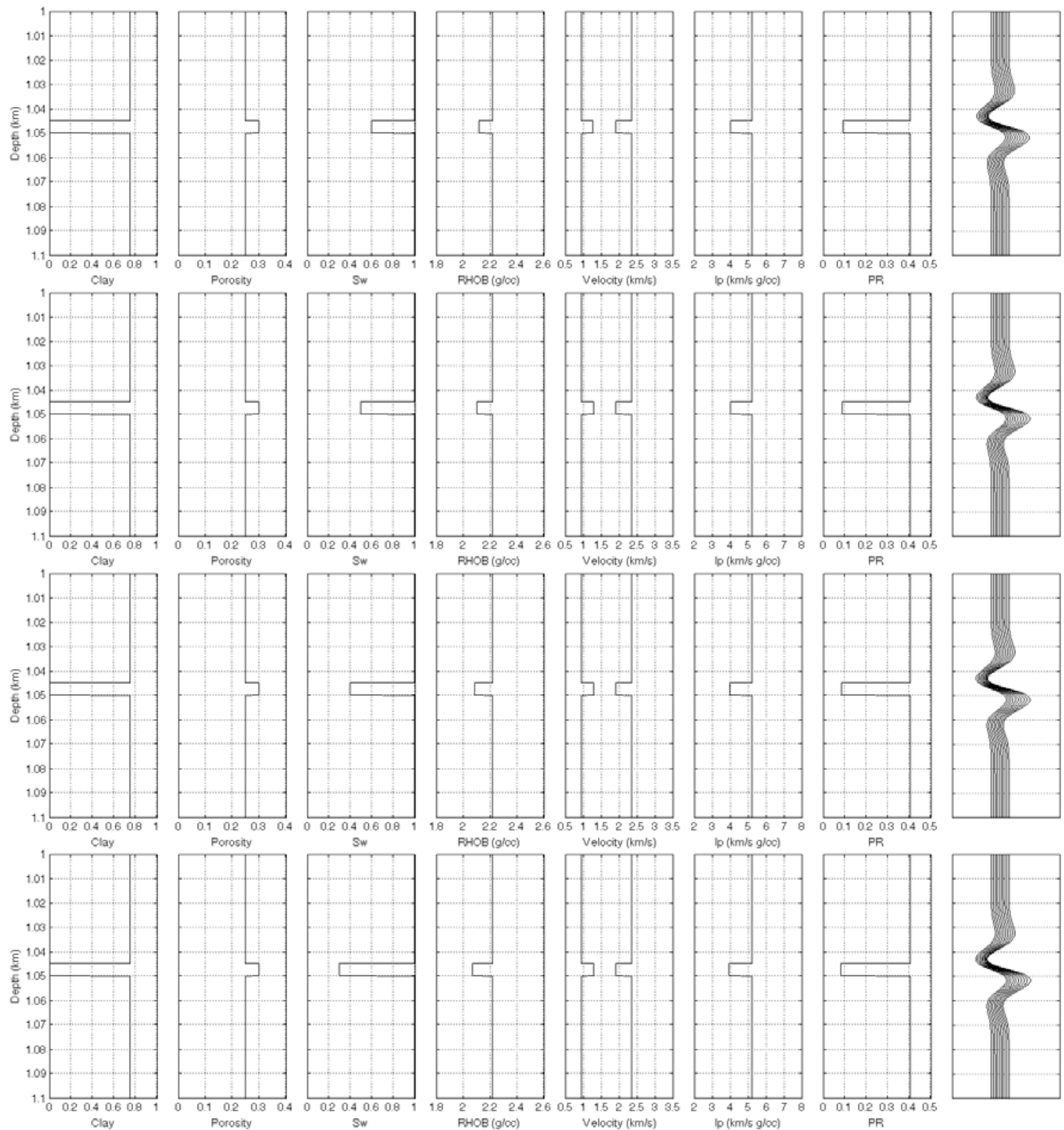

Figure 4.6. Same as Figure 4.5 but with $\mathrm{CO}_{2}$ saturation increasing from 40 to $70 \%$ (top to bottom). 
This behavior is consistent with the results of traditional (Gassmann's) fluid substitution on the elastic properties as shown in Figures 2.7, 2.8, and 4.3 (blue curves). This means that if the elastic properties depend on $\mathrm{CO}_{2}$ saturation according to the traditional fluid substitution (Gassmann's) theory where the bulk modulus of the "effective" pore fluid is the harmonic average of the fluid phases, we may not be able to quantify $\mathrm{CO}_{2}$ saturation from the seismic response.

On the other hand, if the elastic properties depend on $\mathrm{CO}_{2}$ saturation according to CPET theory (red symbols in Figures 2.7, 2.8, and 4.3), we expect more gradual variation of the elastic properties as a function of gas saturation and, as a result, viable saturation prediction from seismic data. Indeed, the synthetic seismic reflections from the same reservoir shown in Figures 4.4 to 4.6 but using CPET-based fluid substitution show gradual transition of the seismic response (Figure 4.7). This result may open the possibility of tracking $\mathrm{CO}_{2}$ saturation from seismic data.
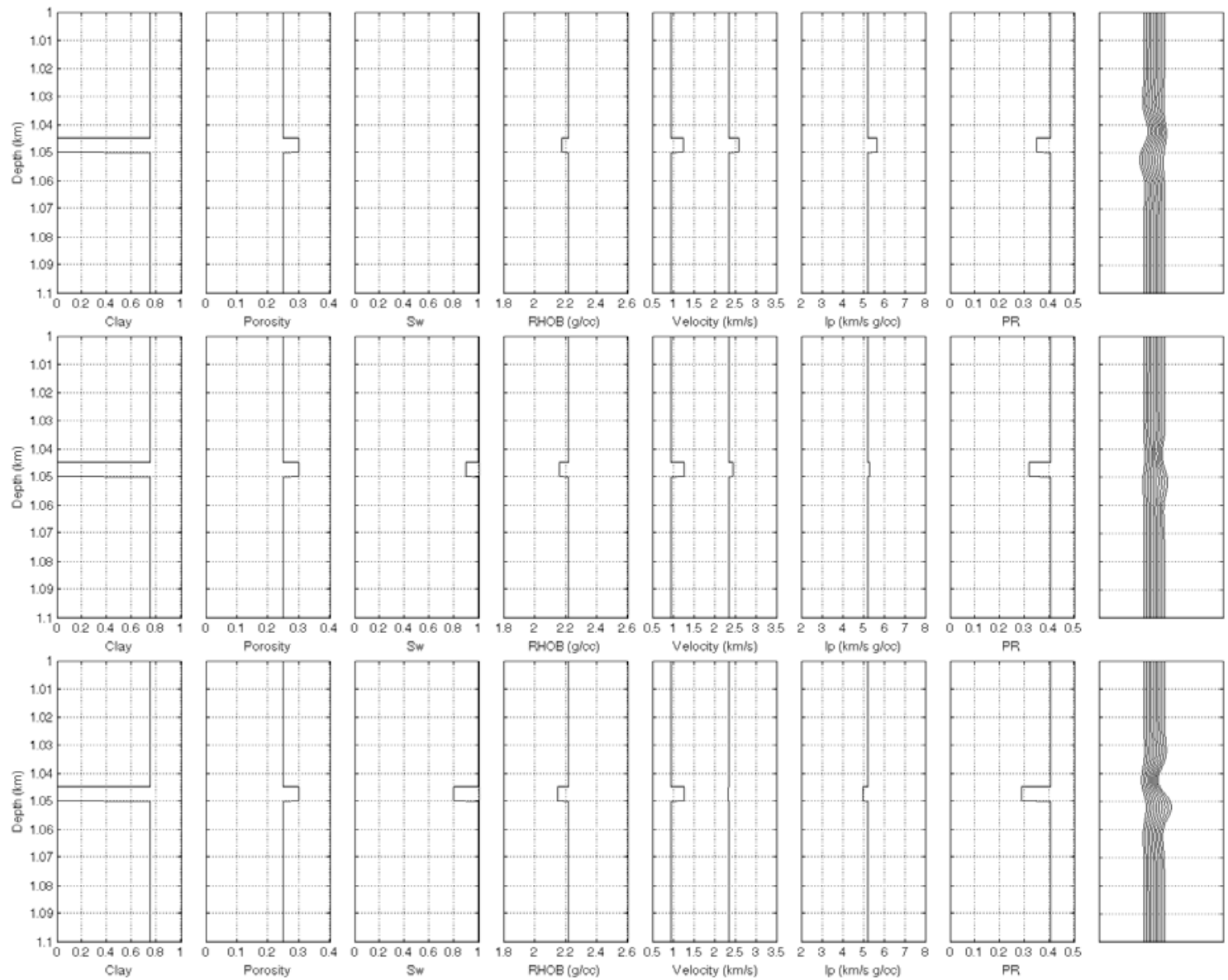

Figure 4.7. Continued into next page. 

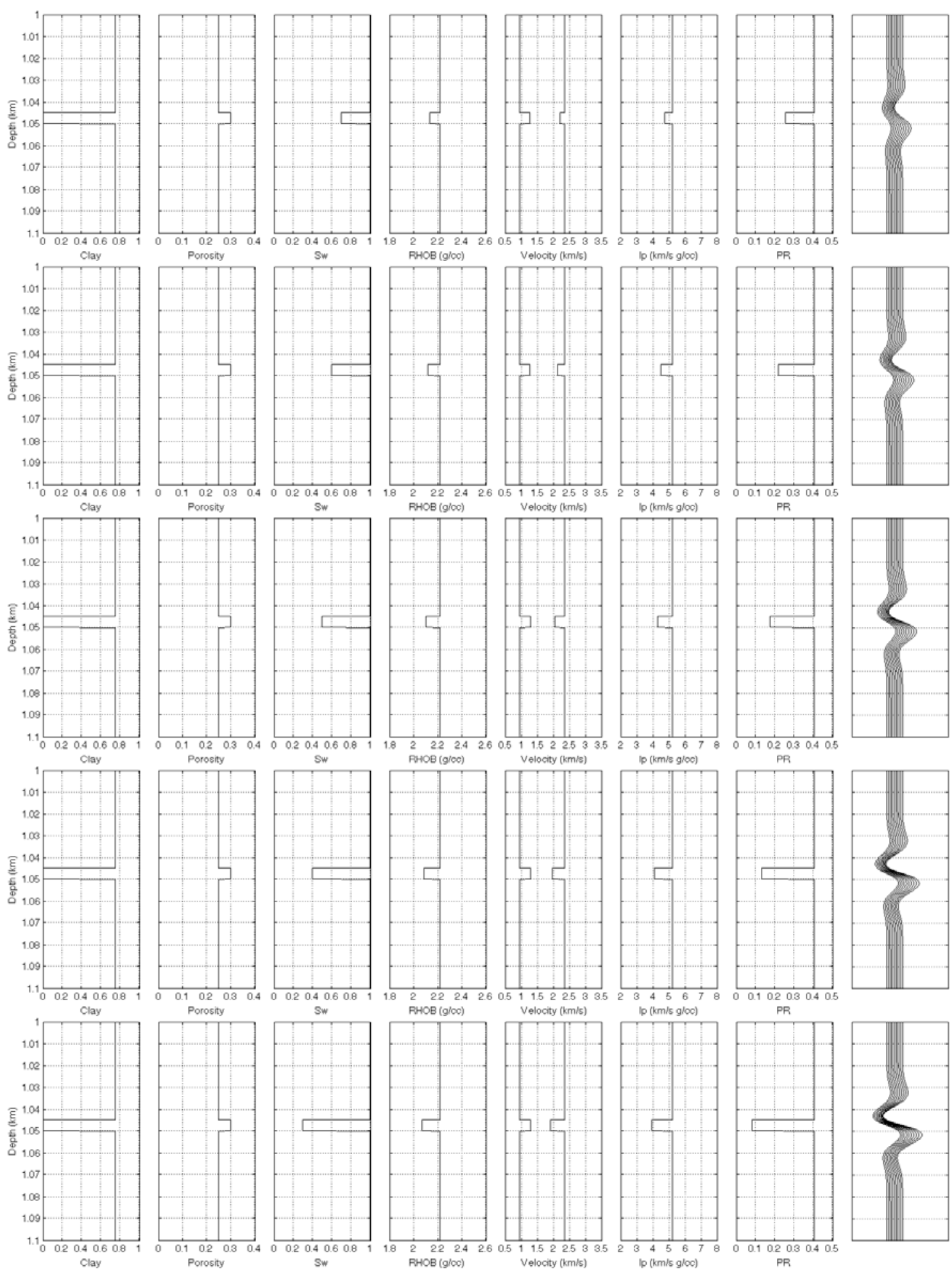

Figure 4.7. Continued from previous page. Same as Figures 4.4 to 4.6 but using CPET fluid substitution. Water saturation gradually decreases from $100 \%$ in the first row (previous page) to $30 \%$ (bottom row). The respective $\mathrm{CO}_{2}$ saturation increases from zero to $70 \%$. 
To further emphasize this result, in Figure 4.8 we compare the seismic gathers generated at varying $\mathrm{CO}_{2}$ saturation using the traditional fluid substitution and CPETbased fluid substitution.
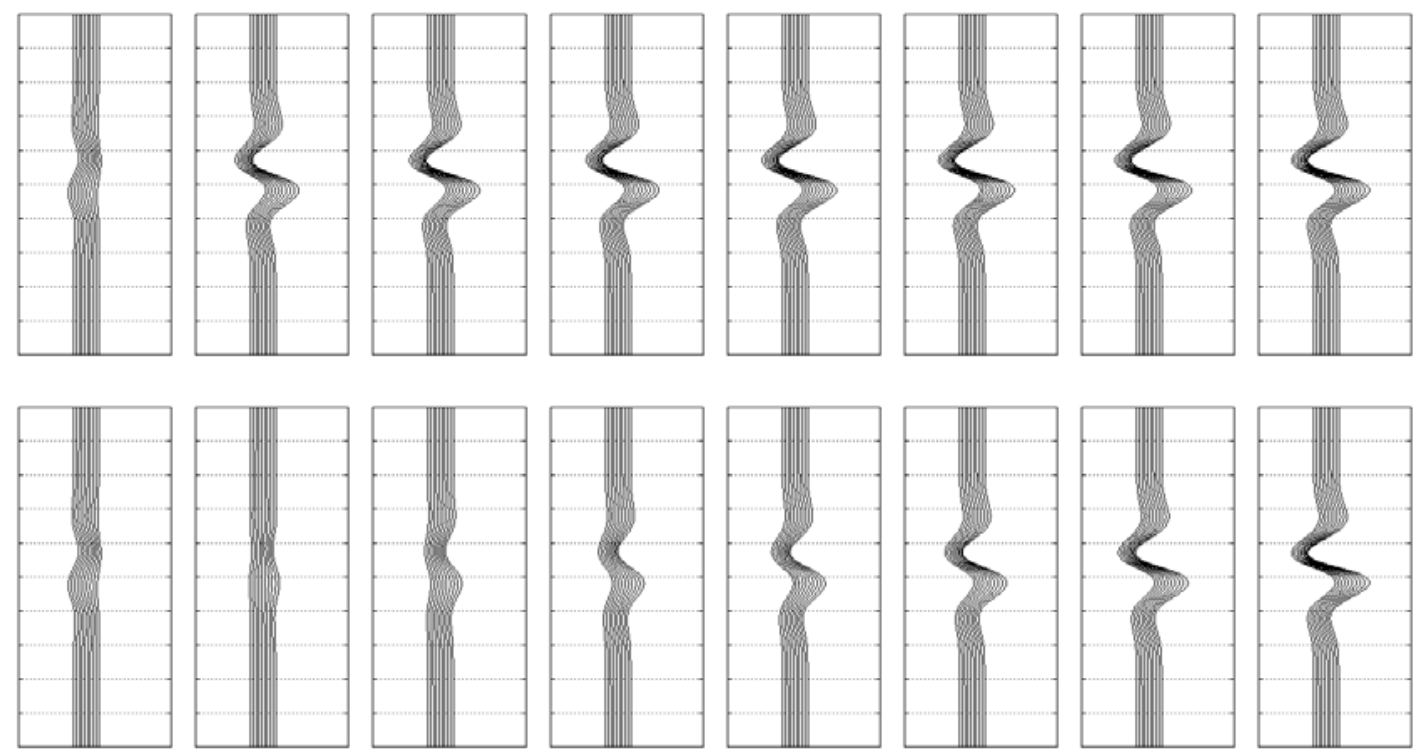

Figure 4.8. Synthetic seismic gathers (Figures 4.4 to 4.7) as $\mathrm{CO}_{2}$ saturation gradually increases from zero to $70 \%$ with $10 \%$ increment (left to right). Top: Traditional (Gassmann's) fluid substitution. Bottom: CPET-based fluid substitution. While the seismic response versus saturation behavior is abrupt in the top row, it is gradual in the bottom row, which may provide a rock physics foundation for monitoring in-situ $\mathrm{CO}_{2}$ saturation from seismic surveys. 


\section{Additional Comments on Fluid Substitution Effects}

Rock Type. Examples discussed here are based on soft rock where the changes in the fluid strongly affect the elastic properties. In stiffer reservoirs, the fluid substitution effects will have smaller influence on the elastic properties of rock and, hence, it may be much more difficult to track $\mathrm{CO}_{2}$ saturation from seismic data.

$\mathbf{C O}_{2}$ Phase. Examples discussed here are based on the assumption that $\mathrm{CO}_{2}$ is gas. In this case, we expect to observe the largest elastic contrasts between the seismic responses of a wet saline reservoir and that where gas was introduced. The smaller the elastic and density contrasts between the brine and $\mathrm{CO}_{2}$ phase injected into the reservoir the smaller the effect on the elastic properties of the host rock and, as a result, on the difference in seismic response. The methods developed in this work are applicable to any $\mathrm{CO}_{2}$ phase. In the examples presented here, we used gas $\mathrm{CO}_{2}$ to emphasize the rockphysics-based effects of $\mathrm{CO}_{2}$ sequestration.

Experimental Confirmation. CPET theory in essence validates and uses first principles to explain the patchy saturation theory discussed in, e.g., Mavko et al. (2009). A number of experimental datasets confirm the CPET-predicted behavior of the elastic properties of rock as a function of saturation. The latest example confirming such behavior is by Lebedev et al. (2013). 


\section{Changes in Elastic Properties of Dry Frame and its Seismic Effects}

Rock Frame Changes During Sequestration. Several effect may occur during CO2 sequestration that will alter the porosity, permeability, and the elastic properties of the host rock frame. Although such effects may occur simultaneously, we will separate them into three categories:

(a) Elastic property variation due to changes in injection pressure;

(b) Alteration of the pore space and elastic property changes as $\mathrm{CO}_{2}$ gets dissolved in the brine; and

(c) Alteration of the frame in carbonate rock due to chemical reaction with $\mathrm{CO}_{2-}$ acidized pore fluid.

Each category will be examined separately from each other.

Pore Pressure Variations. The combined effects of pore pressure and gas saturation variations on the elastic properties of rock during $\mathrm{CO}_{2}$ sequestration will be examined using an example from the Troll dataset. Specifically, the sample we will examine has porosity 0.35 and dry-rock density $1.762 \mathrm{~g} / \mathrm{cc}$. Its permeability at room conditions is $2773 \mathrm{mD}$. We will assume that this permeability does not significantly vary with confining pressure. The elastic property variations with confining stress are listed in Table 6.1. Figure 6.1 shows the variations of these properties versus the confining stress.

Table 6.1. Confining stress dependence of the elastic properties of a room-dry Troll sample. From left to right: Confining stress, porosity, bulk density, permeability, compressional modulus, shear modulus, and the P- and S-wave velocity.

\begin{tabular}{|l|l|l|l|l|l|l|l|}
\hline Stress (MPa) & Porosity & Density $(\mathrm{g} / \mathrm{cc})$ & $k(\mathrm{mD})$ & $M(\mathrm{GPa})$ & $G(\mathrm{GPa})$ & $V_{p}(\mathrm{~km} / \mathrm{s})$ & $V_{s}(\mathrm{~km} / \mathrm{s})$ \\
\hline 5 & 0.350 & 1.762 & 900 & 5.9274 & 2.6878 & 1.8341 & 1.2351 \\
\hline 10 & 0.350 & 1.762 & 900 & 7.0914 & 3.0566 & 2.0061 & 1.3171 \\
\hline 15 & 0.350 & 1.762 & 900 & 7.9053 & 3.3512 & 2.1181 & 1.3791 \\
\hline 20 & 0.350 & 1.762 & 900 & 8.3672 & 3.6542 & 2.1791 & 1.4401 \\
\hline 30 & 0.350 & 1.762 & 900 & 9.0567 & 3.7770 & 2.2672 & 1.4641 \\
\hline
\end{tabular}

Figure 6.1 also shows the confining stress behavior of the wet sample computed from the room-dry data by Gassmann's fluid substitution. The properties of the brine used are the same as in the previous examples, namely, the bulk modulus $K_{w}=3.019 \mathrm{GPa}$ and 
density $\rho_{w}=1.075 \mathrm{~g} / \mathrm{cc}$.
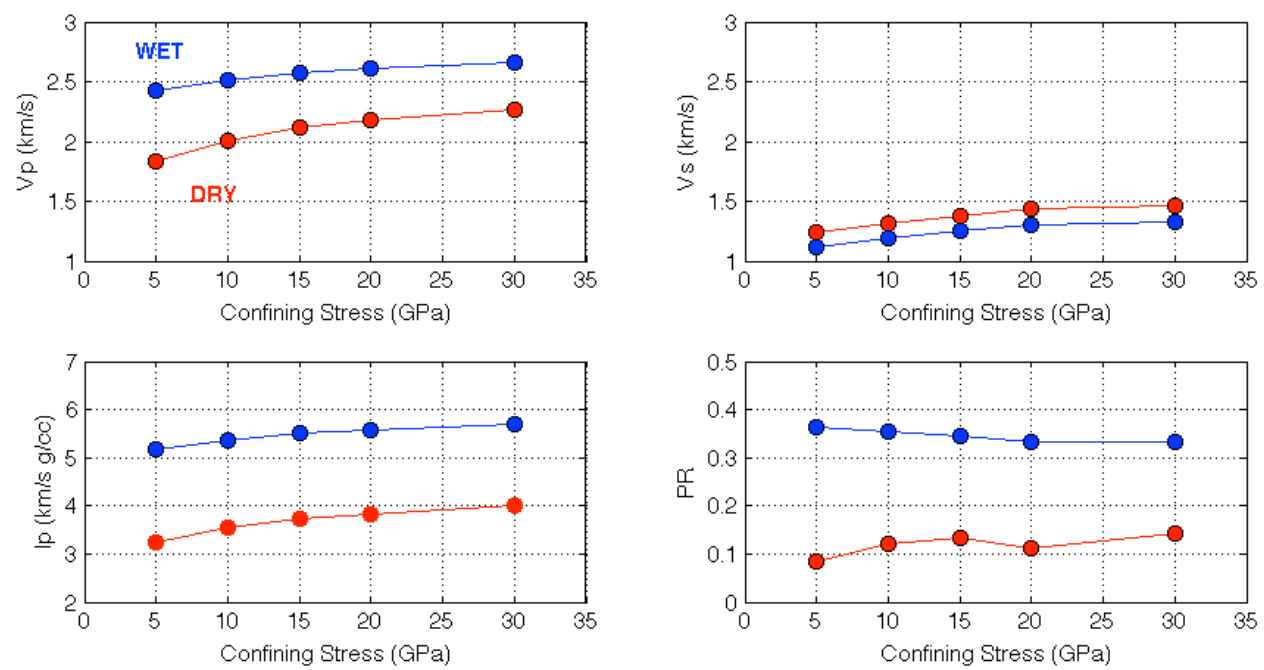

Figure 6.1. Velocity, impedance, and Poisson's ratio of a Troll sample versus confining stress. Red symbols are for the room-dry data (as measured in the laboratory). Blue symbols are for the wet rock computed using fluid substitution for $100 \%$ brine saturation with the brine properties the same as used in the previous examples.

Let us next assume that the elastic properties of rock depend on the difference between the confining in-situ stress (the overburden) and pore pressure $\left(P_{p}\right)$. Let us also assume that is this example, the overburden confining stress is $35 \mathrm{MPa}$ and the initial pore pressure (prior to sequestration) is $20 \mathrm{MPa}$. This means that the initial differential pressure is $35-20=15 \mathrm{MPa}$. The elastic properties of the sample at these conditions are those from the experimental data listed in Table 6.1 at 15 MPa confining stress.

Let us also assume that during injection, the pore pressure increases by $10 \mathrm{MPa}$ and becomes $30 \mathrm{MPa}$. As a results, the differential pressure decreases and becomes $35-30=$ $5 \mathrm{MPa}$ and the resulting dry-frame elastic properties are those listed in Table 6.1 for 5 MPa confining stress. The dry-rock elastic properties for these two pore pressure stations are listed in Table 6.2 and shown in Figure 6.2.

The bulk moduli of the brine and $\mathrm{CO}_{2}$ gas also depend on the pore pressure. The respective values are also listed in Table 6.2. The variations in the bulk modulus and density of the brine are relatively small, while the bulk modulus of gas $\mathrm{CO}_{2}$ increases by a factor of 2.5 . 
Table 6.2. Pore pressure dependence of the elastic properties of a room-dry Troll sample. From left to right: The dry-rock compressional and shear moduli, P- and S-wave velocity, the bulk modulus and density of the brine, and the bulk modulus and density of $\mathrm{CO}_{2}$ gas.

\begin{tabular}{|l|l|l|l|l|l|l|l|l|}
\hline$P_{p}(\mathrm{MPa})$ & $M(\mathrm{GPa})$ & $G(\mathrm{GPa})$ & $V_{p}(\mathrm{~km} / \mathrm{s})$ & $V_{s}(\mathrm{~km} / \mathrm{s})$ & $K_{w}(\mathrm{GPa})$ & $\rho_{w}(\mathrm{~g} / \mathrm{cc})$ & $K_{g}(\mathrm{GPa})$ & $\rho_{g}(\mathrm{~g} / \mathrm{cc})$ \\
\hline 20 & 7.9049 & 3.3512 & 2.1181 & 1.3791 & 3.0550 & 1.0765 & 0.1016 & 0.7217 \\
\hline 30 & 5.9272 & 2.6879 & 1.8341 & 1.2351 & 3.1287 & 1.0800 & 0.2471 & 0.8378 \\
\hline
\end{tabular}
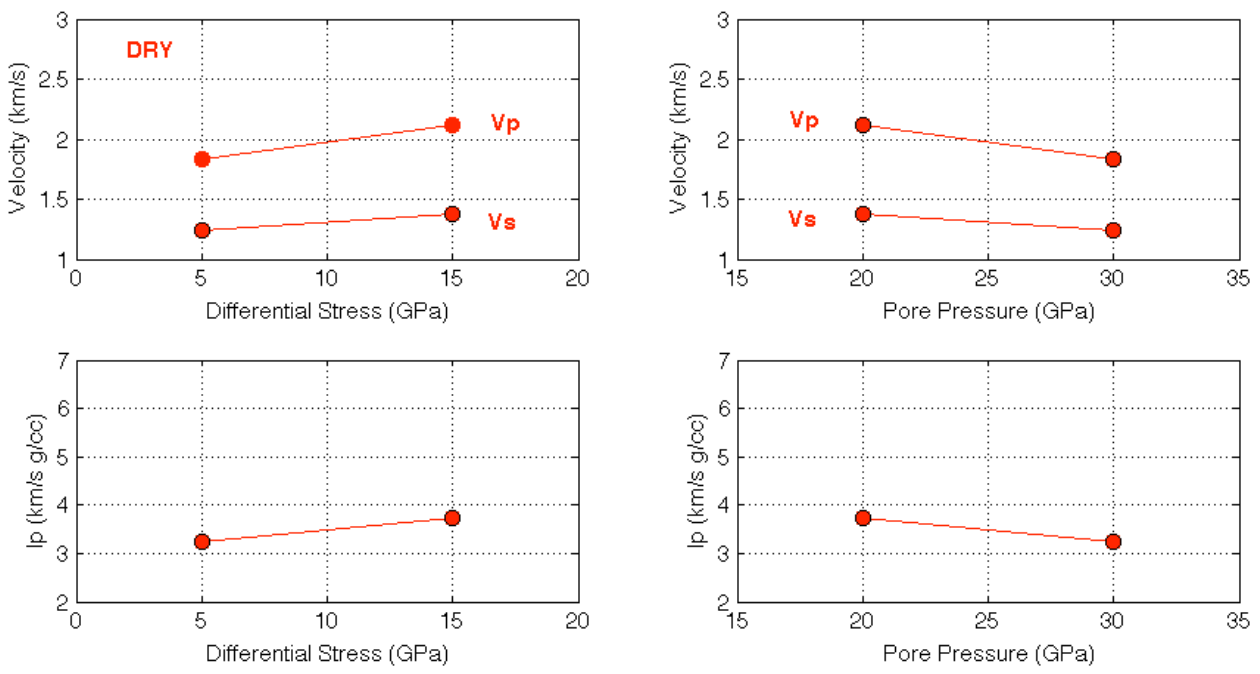

Figure 6.2. Dry-rock velocity (top) and impedance (bottom) versus the differential stress (left) and respective pore pressure (bottom).

Let us assess how significant are the variations in the elastic moduli and velocity of the sample due to the variations in the elastic properties and density of the pore fluid components. To accomplish this, let us examine two end points along the water saturation axis. The first end point is at $100 \%$ brine saturation while the other is at $30 \%$ brine saturation which we will assume here to be the irreducible water saturation. At this irreducible water saturation, the fluid distribution in the rock is uniform, meaning the bulk modulus of the effective pore fluid is the harmonic average of the bulk moduli of the brine and gas. Because fluid substitution effect on the elastic properties becomes larger as the rock becomes softer, for the purpose of this evaluation we will choose the bulk modulus of the sample at highest pore pressure (lowest differential) pressure. This value is $2.343 \mathrm{GPa}$.

The resulting bulk modulus of the sample at $100 \%$ water saturation is $9.0522 \mathrm{GPa}$ for the bulk modulus of the brine 3.0550 GPa and 9.1938 GPa for the bulk modulus of brine 
3.1287 GPa. This difference is about 1.5\%.

At $30 \%$ partial saturation, the harmonically computed bulk modulus of the pore fluid is $0.3414 \mathrm{GPa}$ for the brine bulk modulus $3.1287 \mathrm{GPa}$ and gas bulk modulus $0.2471 \mathrm{GPa}$. The resulting bulk modulus of the sample (computed using Gassmann's fluid substitution) is $3.1845 \mathrm{GPa}$. The bulk modulus of the pore fluid at the same saturation but with the gas bulk modulus $0.1016 \mathrm{GPa}$ is $0.1432 \mathrm{GPa}$. The resulting bulk modulus of the sample is $2.6990 \mathrm{GPa}$. The difference is about $18 \%$.

The latter difference appears to be substantial, yet it is very small as compared to the bulk modulus difference between 30 and 100\% water saturation (Figure 6.3). Hence, for all practical purposes, we can assume constant bulk moduli and densities of the brine and $\mathrm{CO}_{2}$ gas as the pore pressure changes. Specifically, in the following computations, we select average properties of brine and gas between 20 and $30 \mathrm{GPa}$ pore pressure as $K_{w}=$ $3.0918 \mathrm{GPa} ; \rho_{w}=1.0783 \mathrm{~g} / \mathrm{cc} ; K_{g}=0.1744 \mathrm{GPa}$; and $\rho_{g}=0.7797 \mathrm{~g} / \mathrm{cc}$.

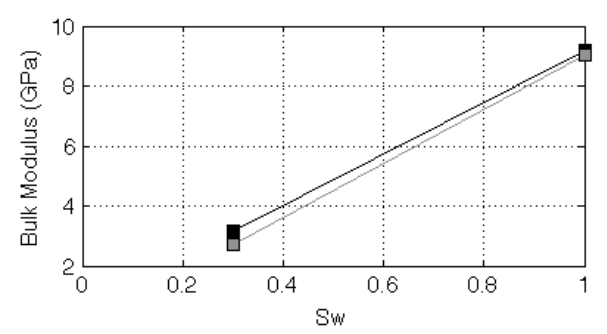

Figure 6.3. Bulk modulus versus saturation (only at saturation points 30 and $100 \%$ ) for the sample under examination and for two sets of the elastic properties of brine and gas, as explained in the text.

Let us next conduct heterogenezation of the data as described earlier for CPET fluid substitution on a datum. As before, we will assume that the porosity can randomly vary around its mean, which is 0.35 , in the interval between 0.30 and 0.40 . The permeabilityporosity model used here is exactly the same as used in the "heterogenezation" section. However, in order to proceed with conducting elastic heterogenezation, we need to establish a data-consistent velocity-porosity model.

An appropriate model is the soft-sand model used before. Specifically, we establish two types of model curves, one to match the dry-rock data at low pore pressure (high differential pressure) and the other at high pore pressure (low differential pressure). These model curves are shown in Figures 6.4 for both P- and S-wave velocity. 

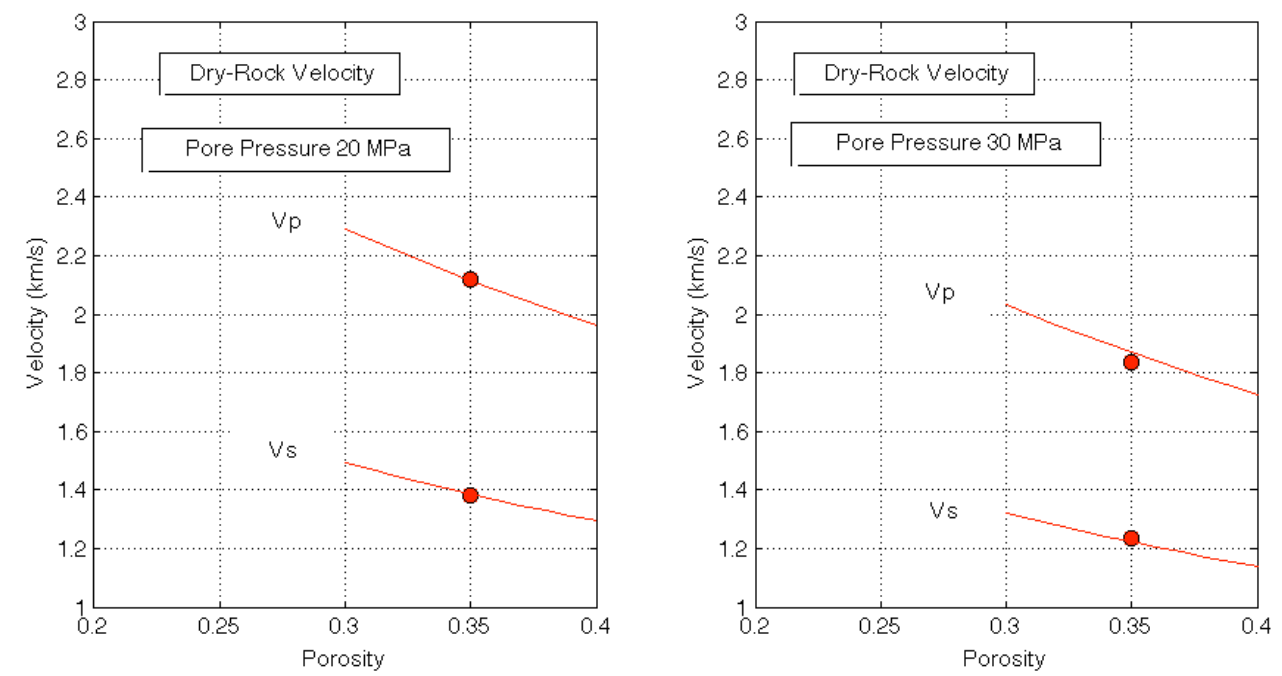

Figure 6.4. Velocity versus porosity in room-dry rock at low pore pressure (left) and high pore pressure (right). The symbols are for laboratory data while the curves are from the soft-sand model with the parameters chosen to match the data.

The final impedance versus saturation and Poisson's ratio versus saturation curves are shown in Figure 6.5 for low pore pressure and Figure 6.6 for high pore pressure.
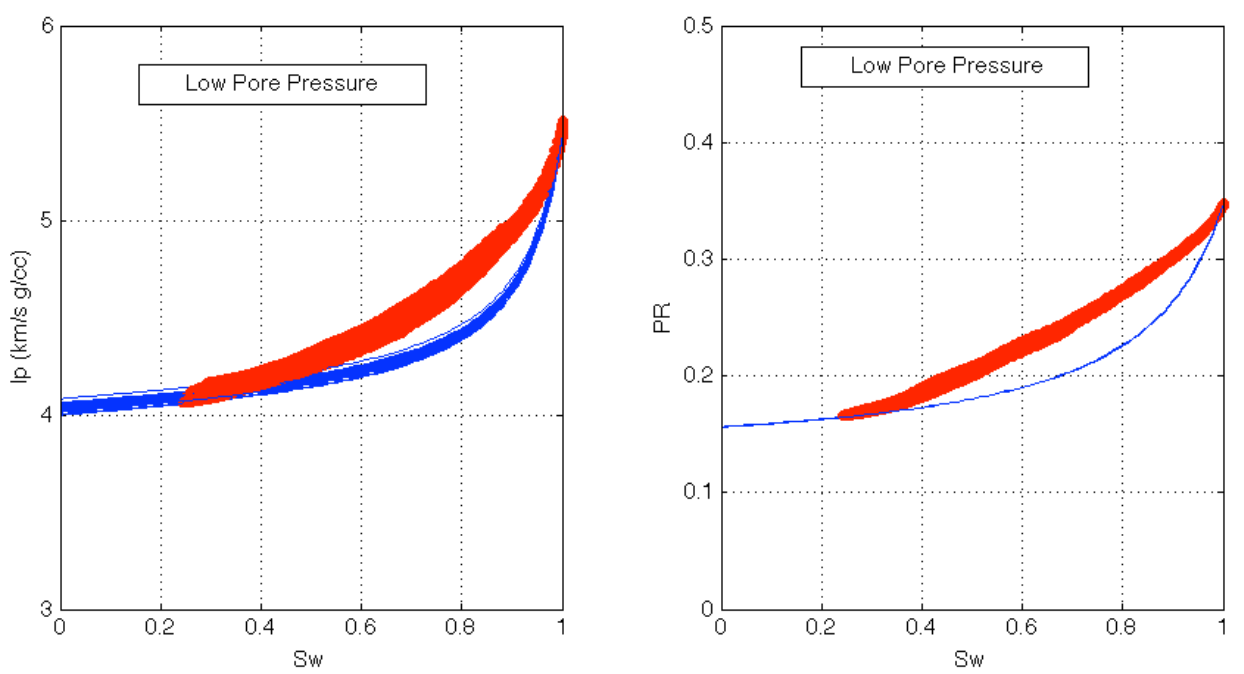

Figure 6.5. Impedance (left) and Poisson's ratio (right) versus saturation according to CPET (red symbols) and Gassmann's fluid substitution (blue curves). These results are for low pore pressure.

Figure 6.7 compares the CPET predictions for low and high pore pressure. In this case, both effects, one due to the fluid change and the other due to pore pressure increase, add up to further reduce the P-wave impedance from its original value at $100 \%$ water 
saturation and low pore pressure conditions.
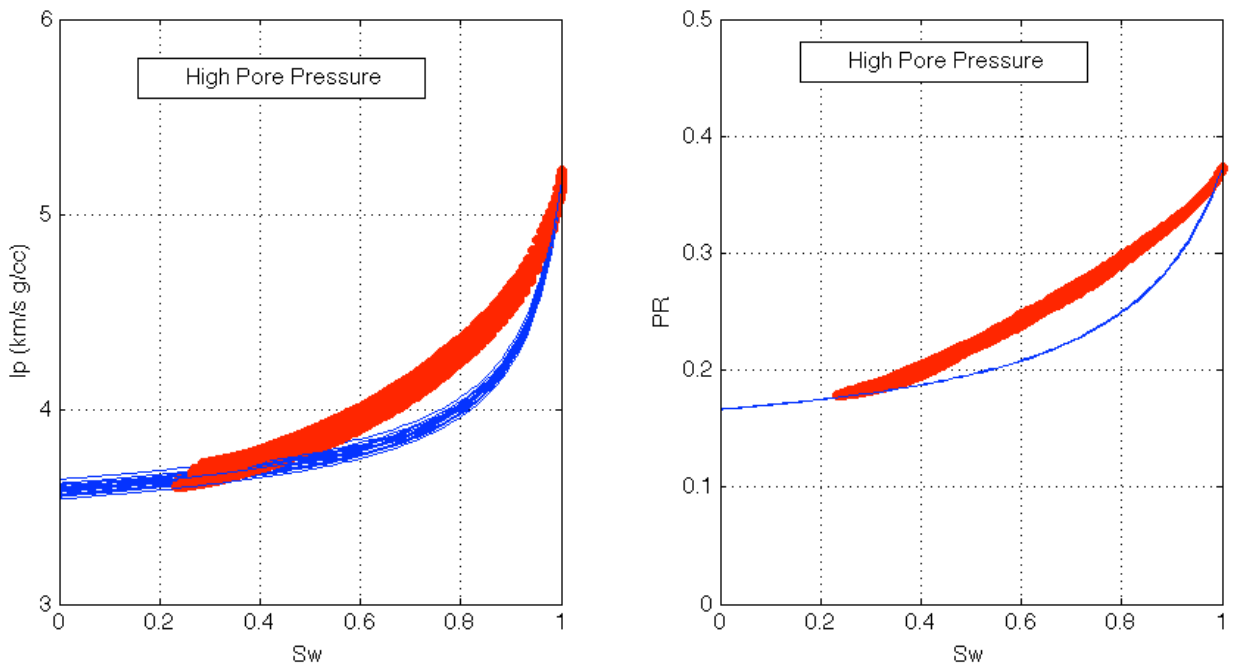

Figure 6.6. Same as Figure 6.5 but for high pore pressure.
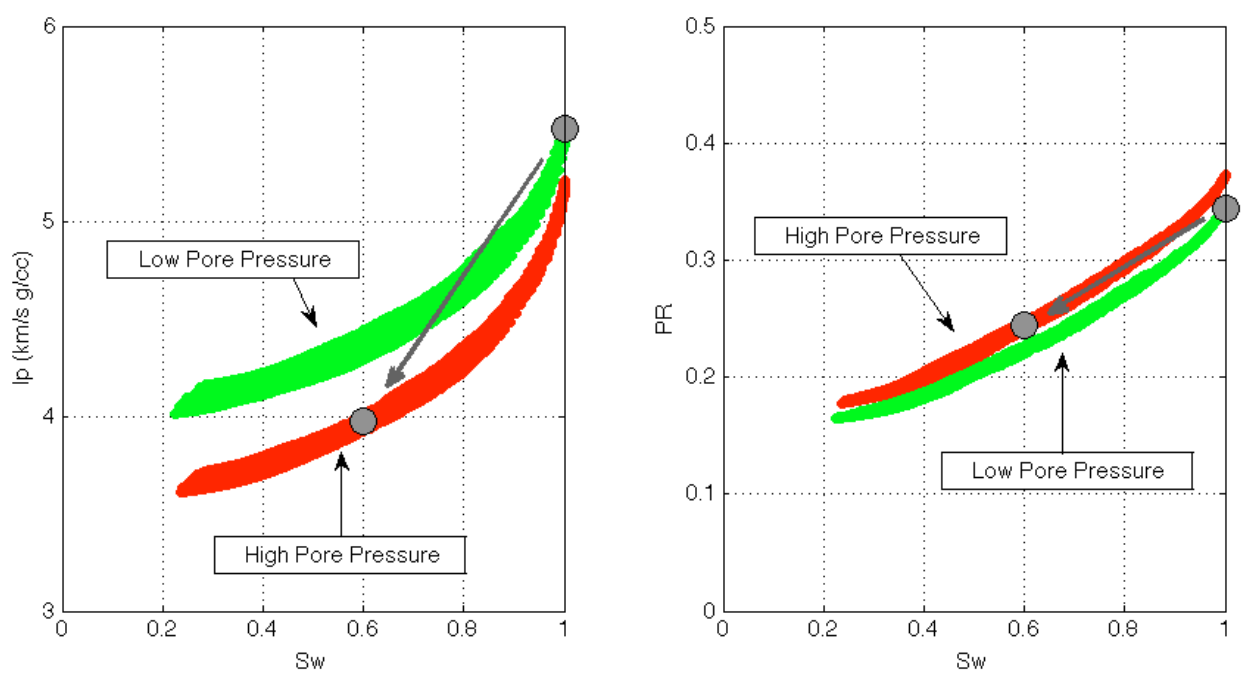

Figure 6.7. CPET results for low (green) and high (red) pore pressure (combined results from Figure 6.4 and 6.5). The arrows indicate the transition from the initial (100\% saturation and low pore pressure) condition to the $40 \% \mathrm{CO}_{2}$ saturation and high pore pressure condition.

Figure 6.7 also indicates that the effect of the pore pressure on Poisson's ratio is small. At fixed saturation, the low-pore-pressure Poisson's ratio is slightly smaller than the high-pore-pressure Poisson's ratio. However, the difference is negligible as compared to the difference due to pore fluid change.

The resulting synthetic seismic response between shale and initially wet sand and the 
same shale and high-pore-pressure sand with $\mathrm{CO}_{2}$ is shown in Figure 6.8. It is very similar to the response shown in Figures 3.6 to 3.8 (strong AVO Class III), however in this case, this response is further enhanced by the softening of the rock frame due to increased pore pressure.
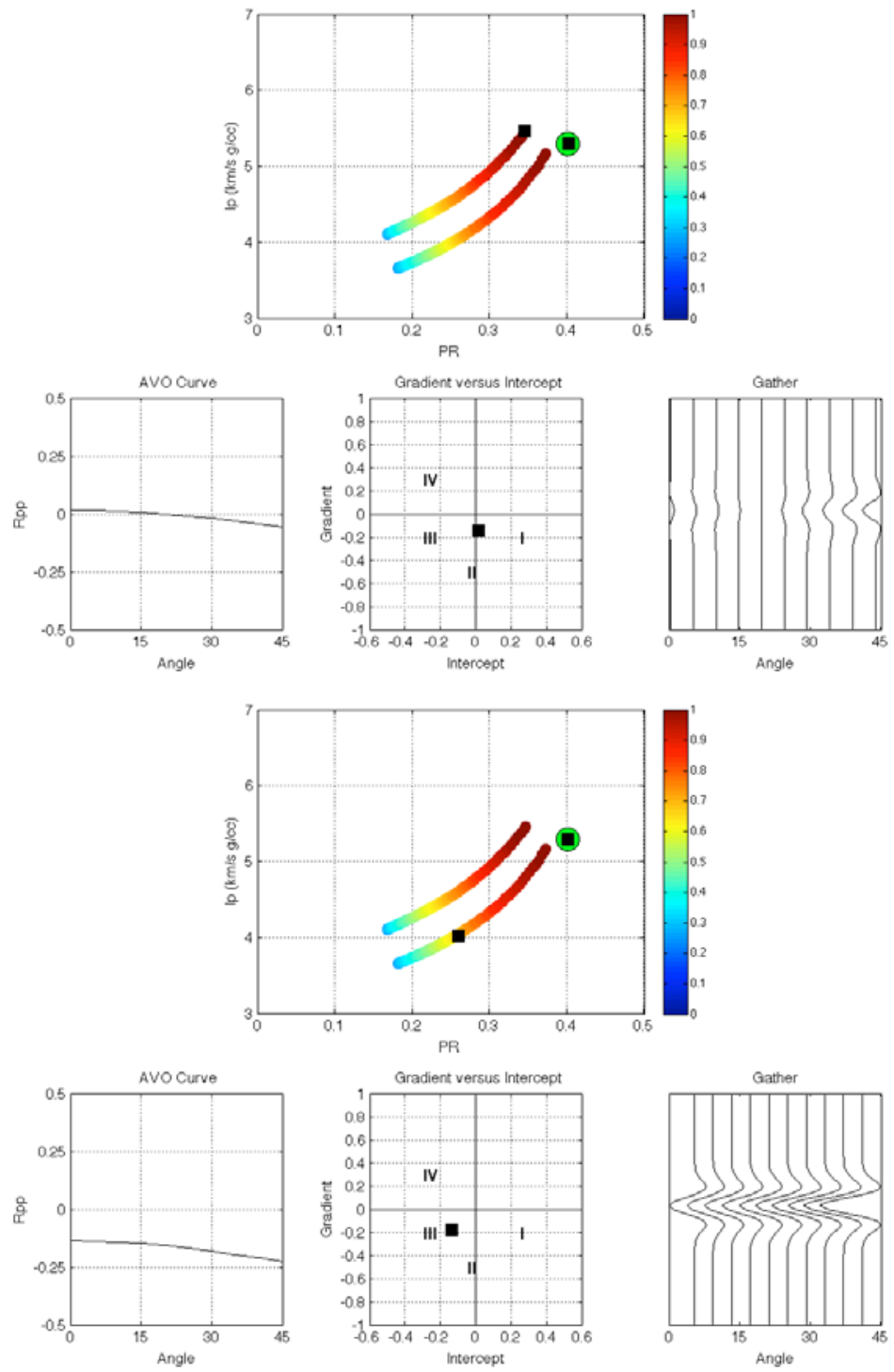

Figure 6.8. Same as synthetic seismic panels shown in Section 3. Top: Reflection between shale and wet sand at low pore pressure and $100 \%$ water saturation. Bottom: Reflection between shale and sand at about $35 \% \mathrm{CO}_{2}$ saturation at high pore pressure. The two impedance versus Poisson's ratio trends color-coded by water saturation in the top panels are similar to those shown in Figure 6.7 (left), except that here we plot the impedance versus Poisson's ratio rather than water saturation. The upper trend is for low pore pressure (stiffer rock frame) while the lower trend is for high pore pressure (softer rock frame). 
Alteration of the Pore Space in Sandstone. Experimental measurements of the elastic-wave velocity and porosity in Tuscaloosa sandstone samples before and after these samples were flushed with $\mathrm{CO}_{2}$-rich brine indicated that both the $\mathrm{P}$ - and $\mathrm{S}$-wave dry-rock velocity decrease after the injection of between 100 and 200 pore volumes. Concurrently, the porosity of the samples decreased as well. A qualitative explanation for the reduction of the elastic-wave velocities is the removal of the clay-rich contact cement originally lodged between the sand grains. Because, due to the removal of the cement, the flushed rock becomes more compliant, its porosity reduces under the applied stress more readily than before the flushing. We quantitatively explain the observed phenomena by using the constant-cement rock physics model where we reduce the degree of cementation as well as the clay content in the flushed samples as compared to the original samples.

The experimental data of Joy et al. (2011) indicate that the elastic-wave velocities in four Tuscaloosa sandstone samples reduce after the injection of over a hundred pore volumes of $\mathrm{CO}_{2}$-saturated brine through the samples. One explanation of this effect comes from SEM images of the same sample before and after the injection (Figure 6.9). Specifically, we can speculate that the cement at the grain contacts (i.e., iron-rich chlorite) is partially removed during the injection. Some of this cement might have been dissolved in the $\mathrm{CO}_{2}$-rich brine and permanently removed from the sample thus reducing the overall clay content.

Here we analyze the data from several Tuscaloosa samples subject to $\mathrm{CO}_{2}$ injection. Because the mineralogical content of these samples is not precisely known, we are unable to accurately match the existing data points with theoretical curves. Instead, we produce theoretical curves for quartz/clay mixtures with the standard elastic moduli and density for quartz (36.6 GPa for the bulk modulus; $45.0 \mathrm{GPa}$ for the shear modulus; and $2.65 \mathrm{~g} / \mathrm{cc}$ for the density) and clay (21.0 GPa for the bulk modulus; 7.0 GPa for the shear modulus; and $2.58 \mathrm{~g} / \mathrm{cc}$ for the density). Although the listed properties may be inappropriate for the clay minerals present in these Tuscaloosa samples and, moreover, the mineralogy is much more complex than the assumed quartz/clay mineralogy, the modeling presented here can serve for estimating the relative changes in the actual reservoir. Specifically, to 
describe the samples, we use the stiff-sand (the modilied upper Hashin-Strikman bound) and the constant-cement models. By moving from the velocity-porosity curve generated using the stiff-sand model with a fixed clay content to the velocity-porosity curve generated by the constant-cement model with a relatively smaller clay content, we can explain the velocity reduction due to partial removal of the contact cement.
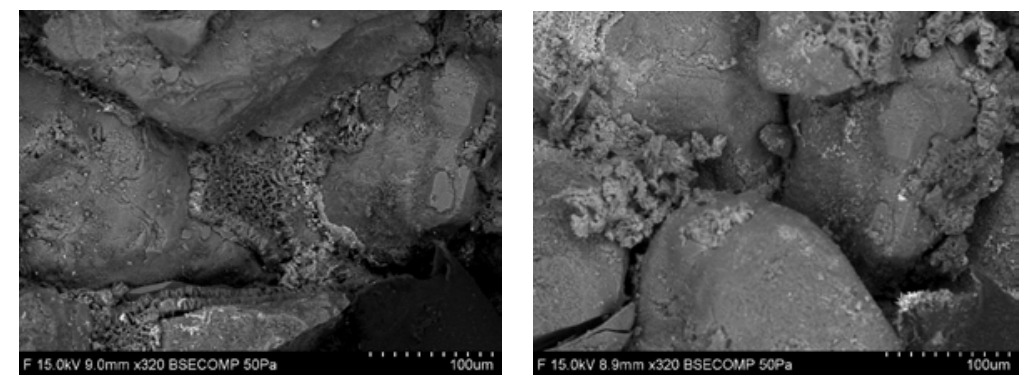

Figure 6.9. SEM images of the same portion of rock before (left) and after (right) injection. The intergranular cement visible on the left is partly removed and, arguably, redeposited away from the grain contacts or removed permanently. Although the location of the SEM image is the same in the original sample and the sample after the injection, it is difficult to identify the original grains as the grains moved during compaction in the loading cell.
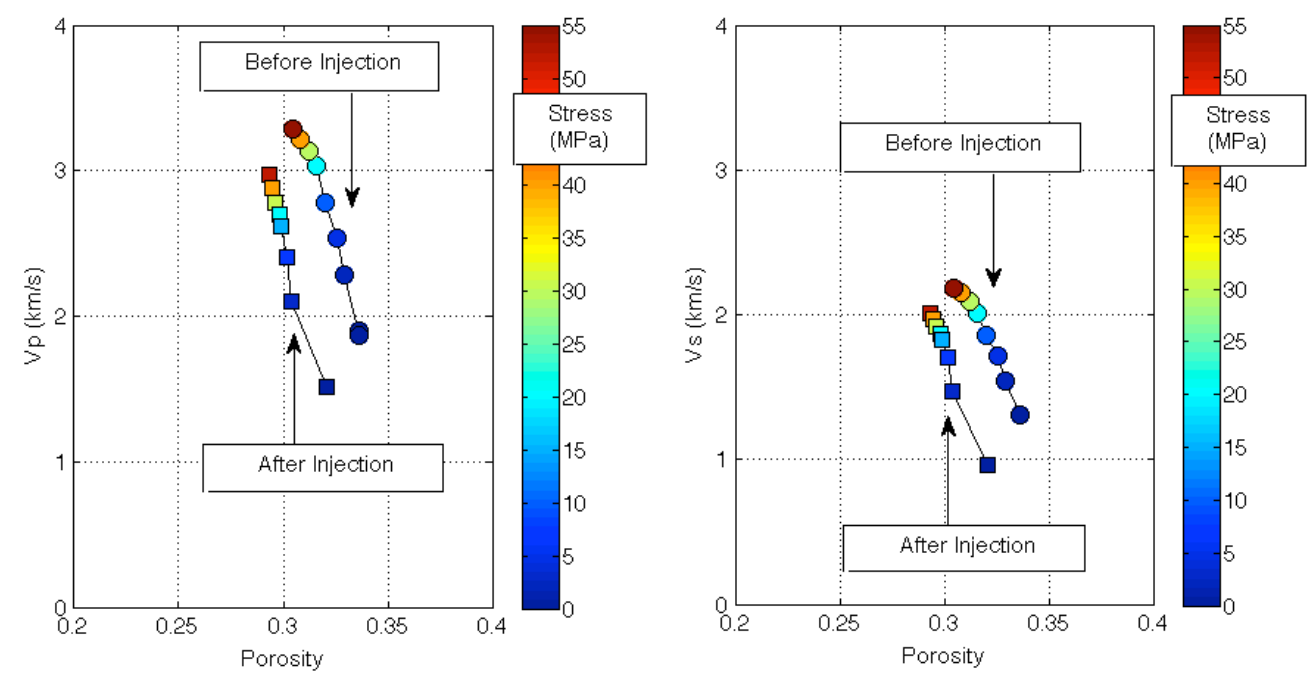

Figure 6.10. P- (left) and S-wave (right) velocity versus porosity for a Tuscaloosa sandstone sample before flooding by $\mathrm{CO}_{2}$-rich brine (circles) and after the flooding (squares). The data are color-coded by the confining stress.

Experimental data on the velocity and porosity changes are shown in Figure 6.10 for a typical sandstone sample. The model curves that approximately match these data are 
shown in Figure 6.11.
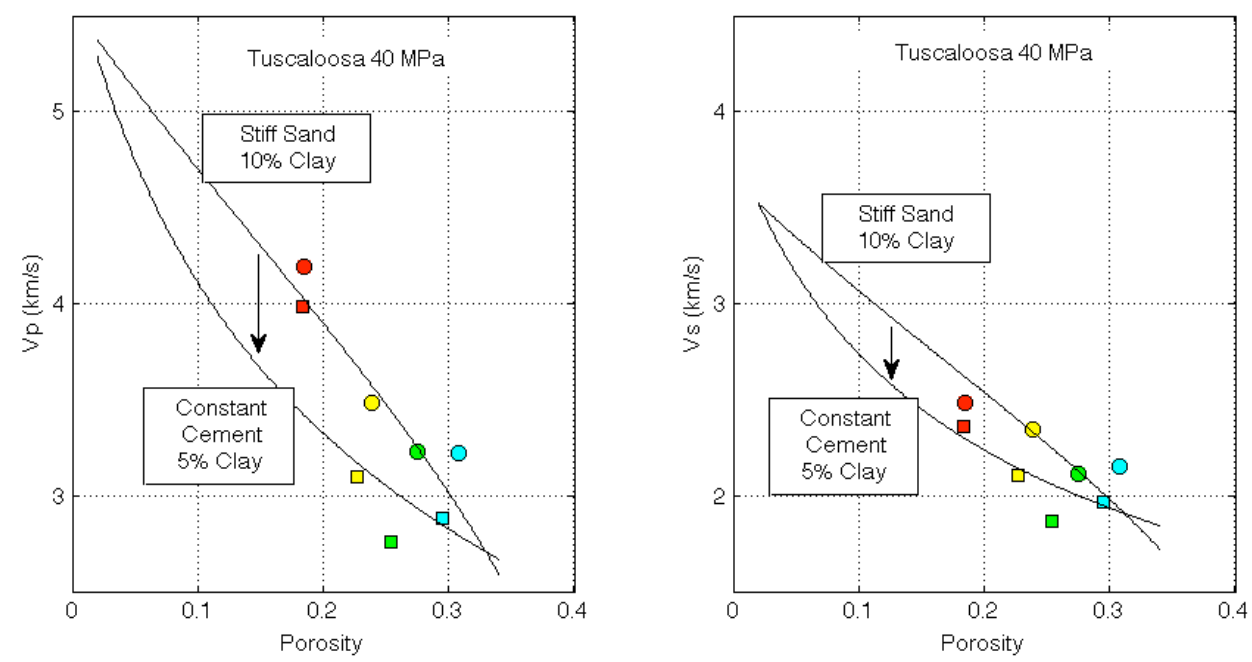

Figure 6.11. Pre-injection (circles) and post-injection (squares) data for the Tuscaloosa samples at 40 MPa confining pressure. The upper curves are from the stiff-sand model for a mixture of $90 \%$ quartz and $10 \%$ clay while the lower curves are from the constant-cement model for a mixture of $95 \%$ quartz and $5 \%$ clay.

Theoretical modeling nonwithstanding, as far as the elastic response is concerned, the situation under examination is very similar to that where the rock frame is softened by increasing pore pressure. As a result of increasing pore pressure during injection, the rock frame will become softer as compared to its initial pre-injection state. This effect will be further enhanced by the chemical softening of the dry frame and cement removal (as illustrated by Figure 6.9). This elastic transition is shown in Figure 6.12.

The overall effect on the seismic reflection of $\mathrm{CO}_{2}$ sequestration is qulitatively similar to that shown in Figure 6.8. It will accompany the reflection between the overburden with presumably unchanged elastic properties to the progressively softening reservoir. The AVO response type will, of course, be driven by the elastic contrast between the overburden and the reservoir.

If the reservoir at its initial conditions is stiffer than the overburden shale, the original AVO Class I may become AVO Class II (Figure 6.12). If the impedance of the reservoir at the initial conditions is approximately the same as that of the overburden, the original AVO Class II may become AVO Class III (Figure 6.13). Finally, if the reservoir at the initial conditions is softer than the overburden, the original AVO Class III will become a 
stronger Class III (Figure 6.14).
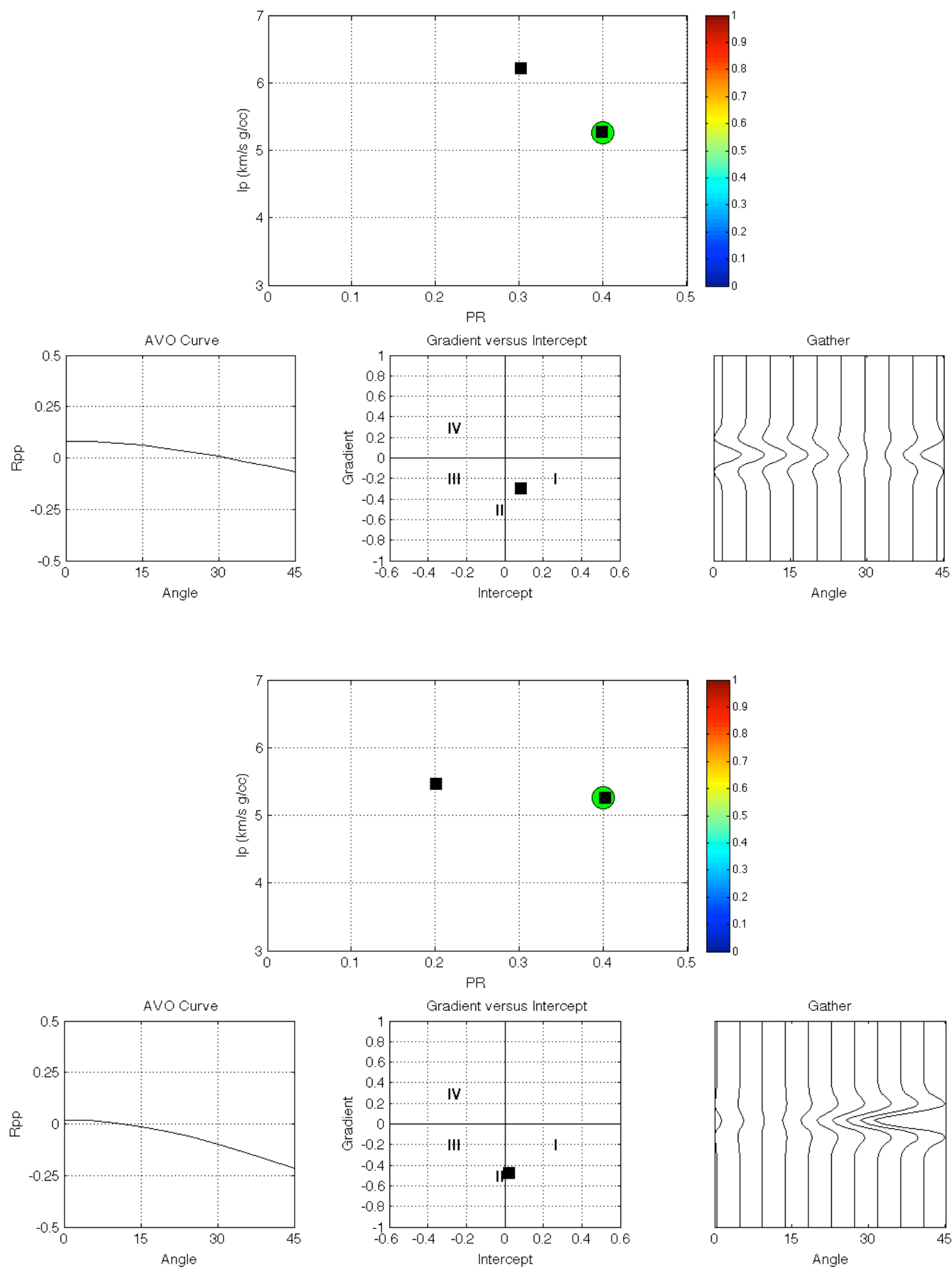

Figure 6.12. AVO response change between the pre-injection conditions (top) and post-injection conditions (bottom) for the case where the reservoir is originally stiffer than the overburden shale. 

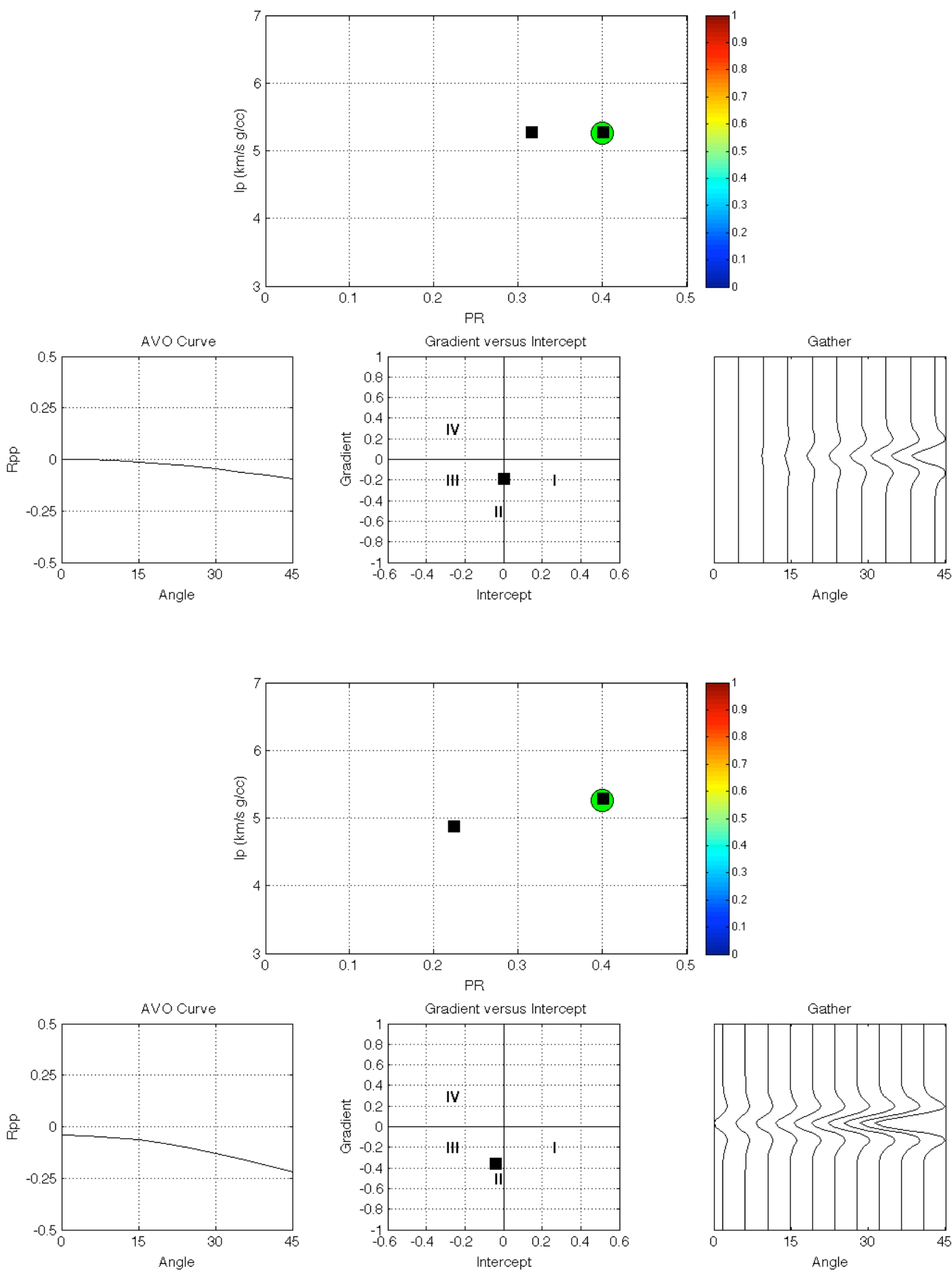

Figure 6.13. AVO response change between the pre-injection conditions (top) and post-injection conditions (bottom) for the case where the reservoir is originally elastically close to the overburden shale. 

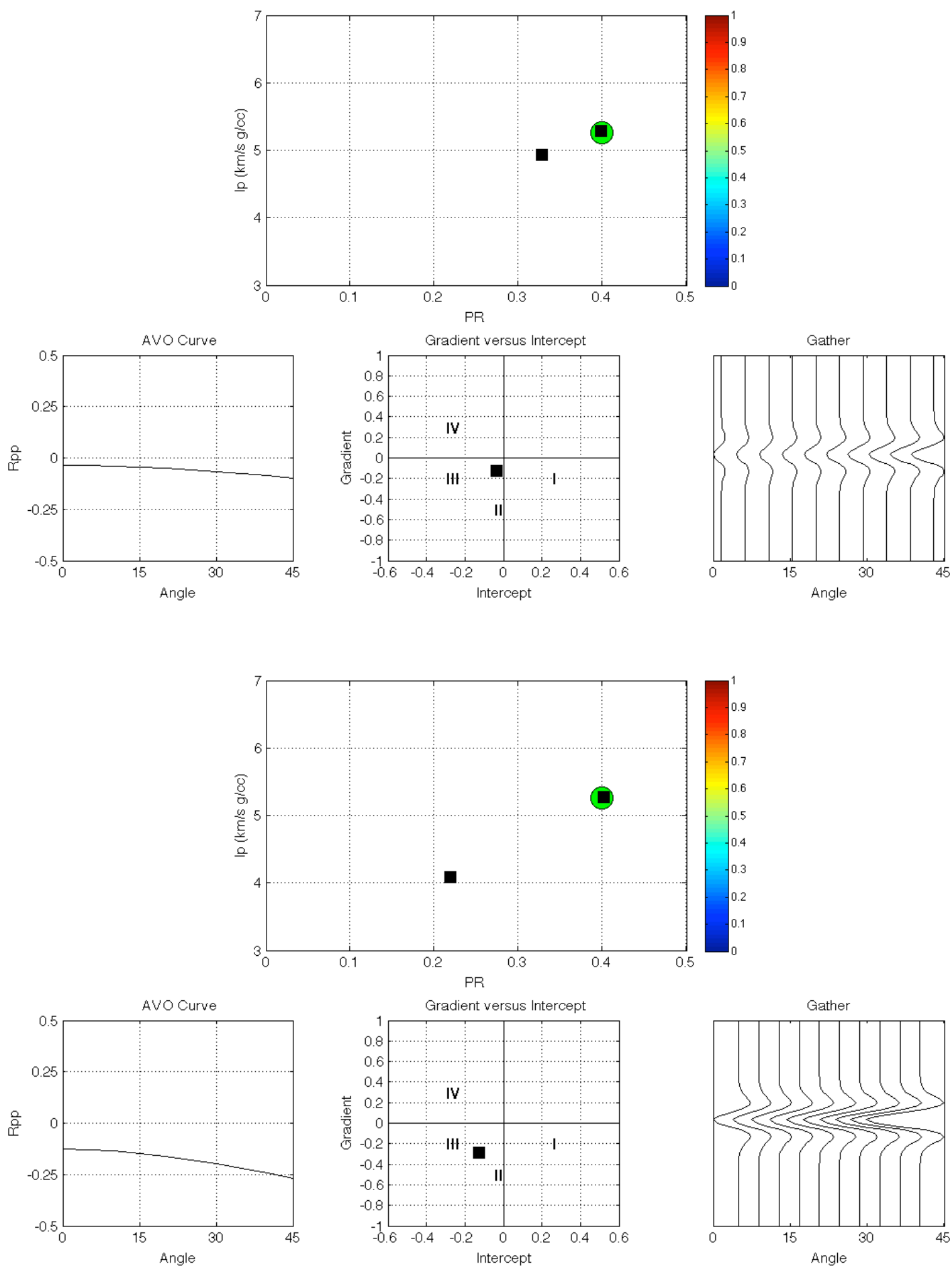

Figure 6.14. AVO response change between the pre-injection conditions (top) and post-injection conditions (bottom) for the case where the reservoir is originally softer than the overburden shale.

Alteration of the Pore Space in Carbonate. Vanorio et al. (2008). among others, 
have shown that the injection of $\mathrm{CO}_{2}$-rich water in carbonate samples leads to a decrease in the elastic properties. Several competing mechanisms are present, such as calcite dissolution, mechanical removal of micrite fraction, and mechanical compaction due to the applied pressure. Mechanical compaction seems to be smaller than porosity enhancement caused by dissolution; also, it does not fully counteract the increase in porosity due to dissolution and particle removal. Chemical processes, microstructure and changes in elastic properties appear to be strongly linked: elastic moduli cannot be correctly estimated without taking into account the changes in the dry frame, which requires monitoring the variation of the chemical composition of the fluid permeating the rock.

Because the pore space geometry is altered, the permeability of the rock may change as well. This effect alone will not greatly change the CPET fluid substitution results. We have shown in Figures 2.12 and 2.13 that permeability variations do not change the shape of the impedance versus saturation or Poisson's ratio versus saturation curves. They merely change the partial saturation endpoint via changing the irreducible water saturation.

As far as the effect of variations in the elastic properties on the seismic response are concerned, the situation is essentially the same as examined in the previous subsection due to sandstone softening. These responses are illustrated in Figures 6.12 to 6.14 and will remain qualitatively similar for carbonate rock. 


\section{Conclusions}

The main contributions of this work to better understanding the seismic reflections of CO2 sequestration are:

Development of the capillary pressure equilibrium theory (CPET) to relate the elastic properties and attenuation of originally wet rock subject to $\mathrm{CO}_{2}$ injection to $\mathrm{CO}_{2}$ saturation. This result indicates that because rock is heterogeneous at all scales, the velocity-saturation behavior is gradual in contrast to abrupt according to the traditional fluid substitution. This means that $\mathrm{CO}_{2}$ saturation can be in principle monitored in-situ using seismic monitoring methods.

Development of CPET-based fluid substitution on well data. This process required "heterogenezation" of the datum, a new development presented and implemented here.

Development of physics-based synthetic seismic catalogues that can serve as a field guide to understand the recorded response and interpreting it in terms of $\mathrm{CO}_{2}$ saturation and containment.

Application of CPET to complex processes where not only the pore fluid but also the rock frame is altered due to mechanical stress as well as mechanical and chemical alteration of the pore space.

In the process of this work, we have trained three students: Amrita Sen (rock physics of $\mathrm{CO}_{2}$ sequestration) who is pursuing her doctoral degree, Nishank Saxena (effective elastic theories and computational rock physics) who is currently pursuing his Ph.D. degree, and Dario Grana (rock physics effects of stress and geostatistics-based seismic interpretation), who successfully graduated with a doctoral degree in 2013. 


\section{Graphical Materials List}

Figure 2.1. The P-wave impedance versus porosity (left column) at 15 (top) and 30 (bottom) MPa confining stress for dry (red) and fully water saturated (wet) conditions (blue). The P-wave impedance versus Poisson's ratio (right column) with the same notations as the plots on the left. Page 9.

Figure 2.2. Permeability versus porosity (left) and permeability versus the threshold pressure (right), color-coded by the porosity of the samples. Page 10.

Figure 2.3. Water saturation versus capillary pressure according to Equation 2.1, for irreducible water saturation 0.30 and $l=1.00,1.25$ (solid curve), and 1.50. Page 10.

Figure 2.4. Left: The effective grain size versus the clay content according to Equation 2.8 and for the sand grain size $0.200 \mathrm{~mm}$ and shale grain size $0.002 \mathrm{~mm}$. Middle: Permeability versus the clay content according to Equation 2.5 with the percolation porosity zero, tortuosity 2, and the sand and shale grain sizes used for the plot on the left. Permeability is computed for porosity $0.4,0.2$, and 0.1 as marked in the plot. Right: The irreducible water saturation versus the clay content for the same inputs and three porosity values. Page 12.

Figure 2.5. Ottawa sand and kaolinite mixtures (Yin, 1992). Left: Permeability versus porosity. Middle: Porosity versus clay content. Right: Permeability versus clay content. Page 13.

Figure 2.6. Permeability variation within a composite cube made of 216 (6 x 6 x 6) subsamples randomly drawn from the Troll dataset. Page 14.

Figure 2.7. Impedance (left) and Poisson's ratio (right) versus global water saturation in a composite 343-element cube built from the Troll dataset samples with the elastic properties measured at $15 \mathrm{MPa}$ confining stress. Red symbols are according to CPET while blue curves are according to traditional Gassmann's fluid substitution. The results are for about 200 random realizations. Page 16.

Figure 2.8. Same as Figure 2.7 but for $30 \mathrm{MPa}$ confining stress. Page 16.

Figure 2.9. CPET results from Figures 2.7 and 2.8 for 15 and $30 \mathrm{MPa}$ confining stress. Page 17.

Figure 2.10. Left: Impedance versus Poisson's ratio as water saturation changes for 15 and $30 \mathrm{MPa}$ confining stress data according to CPET (red) and traditional fluid substitution (blue). Right: The same results but color-coded by water saturation (circles for CPET and squares for traditional fluid substitution). Page 18.

Figure 2.11. The inverse quality factor computed according to CPET and using the Troll data at $15 \mathrm{MPa}$ (left) and $30 \mathrm{MPa}$ confining stress (right). Page 19.

Figure 2.12. Same as Figure 2.7 but for the permeability reduced by a factor of 10 (yellow). Red symbols are for the original case (Figure 2.7). The Gassmann fluid 
substitution results remain unchanged. Page 19.

Figure 2.13. Same as Figure 2.12 but for the permeability increased by a factor of 10 (yellow). Page 20.

Figure 3.1. Left: $P$-wave normal to the interface $(I)$ and the reflected $(R)$ and transmitted (T) $P$-waves. Right: $P$-wave at a non-zero angle of incidence. $q_{1}$ is the angle of incidence while $q_{2}$ is the angle of the transmitted wave. The upper elastic half-space is marked by number " 1 " while the lower half-space is marked by number "2." The reflected and transmitted $S$-waves are marked " $R_{S}$ " and " $T_{s}$," respectively. The angles of the reflected and transmitted $S$-waves are $q_{1}$ and $q_{2}$, respectively. Page 22.

Figure 3.2. Elastic AVO modeling. Top: P-wave impedance versus Poisson's ratio. Two points in this graph are selected, the first one for the upper half-space (on the right in this example) and the second one for the lower half-space (on the left). Bottom, from left to right: The AVO curve; gradient versus intercept with AVO class (I to IV) marked in the quadrants; and the seismic gather where the reflected wave traces are plotted versus the angle of incidence. The vertical axis in the gather plot is TWT (two-way travel time) or depth. Page 24.

Figure 3.3. The top panel from Figure 3.2 with the impedance versus Poisson's ratio domains shown for the shale (green circle) and Troll sand at varying water saturation (see colorbar). Page 25.

Figure 3.4. Synthetic reflection between shale and wet sandstone reservoir. Page 26.

Figure 3.5. Same as Figure 3.4 but at high water saturation (low gas saturation). Page 26.

Figure 3.6. Same as Figure 3.5 but at decreasing water saturation (increasing gas saturation). Page 27.

Figure 3.7. Same as Figure 3.6 but at decreasing water saturation (increasing gas saturation). Page 27.

Figure 3.8. Same as Figure 3.7 but at low water saturation (high gas saturation). Page 28.

Figure 3.9. Same as Figure 3.4 but using Gassmann's fluid substitution instead of CPET. Page 28.

Figure 3.10. Same as Figure 3.9 (Gassmann's fluid substitution instead of CPET) at low gas saturation. Page 29.

Figure 3.11. Same as Figure 3.10 but at high gas saturation. Page 29.

Figure 4.1. Histograms of four porosity subsample realizations for a sample with porosity 0.30 subdivided into $343=7^{3}$ subsamples whose porosity can vary within the 0.25 to 0.35 interval. Page 30 .

Figure 4.2. From left to right and top to bottom: Porosity histogram; dry-rock velocity 
versus porosity; dry-rock bulk density versus porosity; and permeability versus porosity. Page 32.

Figure 4.3. Impedance versus water saturation (left) and Poisson's ratio versus water saturation (right) resulting from fluid substitution conducted at a single point in the subsurface with porosity 0.30 and using the heterogenezation method describe here. Page 32.

Figure 4.4. Pseudo-well where a wet sand interval is surrounded by shale. From left to right: Clay content; porosity; water saturation; bulk density; P- and S-wave velocity; P-wave impedance; Poisson's ratio; and the resulting synthetic seismic gather obtained using a ray tracer with a $40 \mathrm{~Hz}$ Ricker wavelet and maximum angle of incidence about $45^{\circ}$. The vertical axis in all plots is vertical depth in km. Page 33.

Figure 4.5. Same as Figure 4.4 but with gradually decreasing water saturation (increasing $\mathrm{CO}_{2}$ saturation) in sand using traditional (Gassmann's) fluid substitution. Gas saturation increases from 10 to 20 to 30\% (top to bottom). Page 33.

Figure 4.6. Same as Figure 4.5 but with $\mathrm{CO}_{2}$ saturation increasing from 40 to $70 \%$ (top to bottom). Page 34 .

Figure 4.7. Continued from previous page. Same as Figures 4.4 to 4.6 but using CPET fluid substitution. Water saturation gradually decreases from $100 \%$ in the first row (previous page) to $30 \%$ (bottom row). The respective $\mathrm{CO}_{2}$ saturation increases from zero to $70 \%$. Page 36 .

Figure 4.8. Synthetic seismic gathers (Figures 4.4 to 4.7 ) as $\mathrm{CO}_{2}$ saturation gradually increases from zero to $70 \%$ with $10 \%$ increment (left to right). Top: Traditional (Gassmann's) fluid substitution. Bottom: CPET-based fluid substitution. While the seismic response versus saturation behavior is abrupt in the top row, it is gradual in the bottom row, which may provide a rock physics foundation for monitoring in-situ $\mathrm{CO}_{2}$ saturation from seismic surveys. Page 37.

Figure 6.1. Velocity, impedance, and Poisson's ratio of a Troll sample versus confining stress. Red symbols are for room-dry data (as measured in the laboratory). Blue symbols are for wet rock computed using fluid substitution for $100 \%$ brine saturation with the brine properties the same as used in the previous examples. Page 40.

Figure 6.2. Dry-rock velocity (top) and impedance (bottom) versus the differential stress (left) and respective pore pressure (bottom). Page 41.

Figure 6.3. Bulk modulus versus saturation (only at saturation points 30 and 100\%) for the sample under examination and for two sets of the elastic properties of brine and gas, as explained in the text. Page 42.

Figure 6.4. Velocity versus porosity in room-dry rock at low pore pressure (left) and high pore pressure (right). The symbols are for laboratory data while the curves are from the soft-sand model with the parameters chosen to match the data. Page 43. 
Figure 6.5. Impedance (left) and Poisson's ratio (right) versus saturation according to CPET (red symbols) and Gassmann's fluid substitution (blue curves). These results are for low pore pressure. Page 43.

Figure 6.6. Same as Figure 6.5 but for high pore pressure. Page 44.

Figure 6.7. CPET results for low (green) and high (red) pore pressure (combined results from Figure 6.4 and 6.5). The arrows indicate the transition from the initial (100\% saturation and low pore pressure) condition to the $40 \% \mathrm{CO}_{2}$ saturation and high pore pressure condition. Page 44.

Figure 6.8. Same as synthetic seismic panels shown in Section 3. Top: Reflection between shale and wet sand at low pore pressure and 100\% water saturation. Bottom: Reflection between shale and sand at about $35 \% \mathrm{CO}_{2}$ saturation at high pore pressure. The two impedance versus Poisson's ratio trends color-coded by water saturation in the top panels are similar to those shown in Figure 6.7 (left), except that here we plot the impedance versus Poisson's ratio rather than water saturation. The upper trend is for low pore pressure (stiffer rock frame) while the lower trend is for high pore pressure (softer rock frame). Page 45.

Figure 6.9. SEM images of the same portion of rock before (left) and after (right) injection. The intergranular cement visible on the left is partly removed and, arguably, redeposited away from the grain contacts or removed permanently. Although the location of the SEM image is the same in the original sample and the sample after the injection, it is difficult to identify the original grains as the grains moved during compaction in the loading cell. Page 47.

Figure 6.10. P- (left) and S-wave (right) velocity versus porosity for a Tuscaloosa sandstone sample before flooding by $\mathrm{CO}_{2}$-rich brine (circles) and after the flooding (squares). The data are color-coded by the confining stress. Page 47.

Figure 6.11. Pre-injection (circles) and post-injection (squares) data for the Tuscaloosa samples at $40 \mathrm{MPa}$ confining pressure. The upper curves are from the stiff-sand model for a mixture of $90 \%$ quartz and $10 \%$ clay while the lower curves are from the constant-cement model for a mixture of 95\% quartz and 5\% clay. Page 48.

Figure 6.12. AVO response change between the pre-injection conditions (top) and postinjection conditions (bottom) for the case where the reservoir is originally stiffer than the overburden shale. Page 49.

Figure 6.13. AVO response change between the pre-injection conditions (top) and postinjection conditions (bottom) for the case where the reservoir is originally elastically close to the overburden shale. Page 50.

Figure 6.14. AVO response change between the pre-injection conditions (top) and postinjection conditions (bottom) for the case where the reservoir is originally softer than the overburden shale. Page 51. 


\section{References and Bibliography}

Joy, C., Vanorio, T., and Sen, M., 2011, Differentiating chemical effects and pressure effects on the elastic properties of the lower Tuscaloosa sandstone in Cranfield, Mississippi by injecting carbon dioxide rich brine, SRB Volume 126, Paper D1.

Lebedev, M., Pervukhina, M., Mikhaltsevitch, V., Dance, T., Bilenko, O., and Gurevich, B., 2013, An experimental study of acoustic responses on injection of supercritical $\mathrm{CO}_{2}$ into sandstones from the Otway Basin, Geophysics, 78, D293-D306.

Mavko, G., Mukerji, T., and Dvorkin, J., 2009, Rock Physics Handbook, $2^{\text {nd }}$ Edition, Cambridge University Press.

Vanorio, T., Scotellaro, C., and Mavko, G., 2008, The effect of chemical and physical processes on the acoustic properties of carbonate rocks, TLE, 27, 1040-1048.

Siggins, A., 2005, Velocity-effective stress response of $\mathrm{CO}_{2}$-saturated sandstones, Exploration Geophysics, 37, 98-103.

Daley, T., Solbau, R,. Ajo-Franklin, J., and Benson, S., 2007, Continuous active-source seismic monitoring of CO2 injection in a brine aquifer, Geophysics, 72, 57-61.

Raef, A., Miller, R., Byrnes, A., and Harrison, W., 2005, Rock physics and seismic modeling guided application of 4D-seismic attributes to monitoring enhanced oil recovery $\mathrm{CO}_{2}$-flood in a thing carbonate reservoir, Hall Gurney field, Kansas, USA, AAPGE Annual Convention, Exploring Energy Systems.

Li, R., Dodds, K., Siggins, A.F., and Urosevic, M., 2006, A rock physics simulator and its application for $\mathrm{CO}_{2}$ sequestration process, Geophysics, 37, 67-62.

Lumley, D., 2010, 4D seismic monitoring of $\mathrm{CO}_{2}$ sequestration, The Leading Edge, 29, 150-155.

Urosevic, M., Shulakova, V., and Sharma, S., 2010, Time-lapse seismic monitoring of $\mathrm{CO}_{2}$ injection into a depleted gas reservoir-Naylor Field, Australia, The Leading Edge, 29, 164-169.

Chadwick, A., Williams, G., Delpine, N., Clochard, V., Labat, K., Sturton, S., Buddensiek, M., Dillen, M., Nickel, M., Lima, A., Arts, R., Neele, F., and Rossi,G., 2010, Quantitative analysis of time-lapse seismic monitoring data at the Sleipner $\mathrm{CO}_{2}$ storage operation, TLE, 29, 170-177.

Purcell, C., Mur, A., Soong, Y., McLendon, T., Haliasmaa, I., and Harbert,W., 2010, Integrating velocity measurements in a reservoir rock sample from the SACROC unit with an AVO proxy for subsurface supercritical $\mathrm{CO}_{2}$, TLE, 29, 192-195.

Sen, A., Dvorkin, J., and Mavko, G., 2011, Fluid substitution in gas/water systems: Revisiting patchy saturation, SEG Expanded Abstract.

Sen, A., Dvorkin, J., and Mavko, G., 2013, Frequency effect in fluid substitution: Capillary pressure equilibrium theory, SEG Expanded Abstract. 


\section{Acronims and Abbreviations}
AVO Amplitude versus offset
CPET Capillary pressure equilibrium theory
MVA Monitoring, verification, and accounting
TLE The Leading Edge (SEG Journal)
SEG Society of Exploration Geophysicists 